\title{
Monocular inhibition reveals temporal and spatial changes in gene expression in the primary visual cortex of marmoset
}

\author{
Yuki Nakagami ${ }^{1}$, Akiya Watakabe ${ }^{1,2}$ and Tetsuo Yamamori ${ }^{1,2,3 *}$ \\ 1 Division of Brain Biology, Department of Neurobiology, National Institute for Basic Biology, Okazaki, Japan \\ ${ }^{2}$ Department of Basic Biology, The Graduate University for Advanced Studies [SOKENDAl], Okazaki, Japan \\ ${ }^{3}$ Section of Brain Science Exploration and Training, National Institute for Physiological Sciences, Okazaki, Japan
}

\section{Edited by:}

Edward M. Callaway, The Salk

Institute for Biological Studies, USA

Reviewed by:

Pavel Osten, Cold Spring Harbor

Laboratory, USA

James A. Bourne, Australian

Regenerative Medicine Institute,

Australia

*Correspondence:

Tetsuo Yamamori, Division of Brain

Biology, Department of

Neurobiology, National Institute for

Basic Biology, 38 Nishigonaka,

Myodaiji, Okazaki, Aichi 444-8585,

Japan.

e-mail: yamamori@nibb.ac.jp
We investigated the time course of the expression of several activity-dependent genes evoked by visual inputs in the primary visual cortex (V1) in adult marmosets. In order to examine the rapid time course of activity-dependent gene expression, marmosets were first monocularly inactivated by tetrodotoxin (TTX), kept in darkness for two days, and then exposed to various length of light stimulation. Activity-dependent genes including HTR1B, HTR2A, whose activity-dependency were previously reported by us, and well-known immediate early genes (IEGs), c-FOS, ZIF268, and ARC, were examined by in situ hybridization. Using this system, first, we demonstrated the ocular dominance type of gene expression pattern in V1 under this condition. IEGs were expressed in columnar patterns throughout layers $I I-V I$ of all the tested monocular marmosets. Second, we showed the regulation of HTR1B and HTR2A expressions by retinal spontaneous activity, because HTR1B and HTR2A mRNA expressions sustained a certain level regardless of visual stimulation and were inhibited by a blockade of the retinal activity with TTX. Third, IEGs dynamically changed its laminar distribution from half an hour to several hours upon a stimulus onset with the unique time course for each gene. The expression patterns of these genes were different in neurons of each layer as well. These results suggest that the regulation of each neuron in the primary visual cortex of marmosets is subjected to different regulation upon the change of activities from retina. It should be related to a highly differentiated laminar structure of marmoset visual systems, reflecting the functions of the activity-dependent gene expression in marmoset V1.

Keywords: activity-dependent, ocular dominance columns, cortical layer, monocular deprivation, immediate early gene, non-human primate, in situ hybridization

\section{INTRODUCTION}

The primary visual cortex (V1) of primates is estimated to occupy more than $30 \%$ of the cerebral cortex (Collins et al., 2012). It has many characteristic features that enable highly complex informational processing, e.g., formation of distinct functional columnar structures (ocular dominance and orientation columns, or color domains, etc.) (Hubel and Wiesel, 1977; Livingstone and Hubel, 1984), or parallel processing (Joels and de Kloet, 1992; Nassi and Callaway, 2009). We previously showed that the expression of a group of genes, such as OCC1 (FSTL1), 5-hydroxytryptamine (serotonin) receptor $1 B$ and $2 A$ (HTR1B and HTR2A, respectively), Testican-1, and Testican-2, are highly enriched in the thalamorecipient layers of $\mathrm{V} 1$ of adult macaques (Tochitani et al., 2001; Takahata et al., 2009; Watakabe et al., 2009). Their V1enriched expression patterns were conserved in several species of primate but not in ferrets and mice (Takahata et al., 2008, 2012), suggesting that there are primate-specific mechanisms for expression of these genes. An important common feature to these genes was the activity-dependent expression in V1, which we showed by monocular inactivation of retinal activity using tetrodotoxin
(TTX) (Tochitani et al., 2001; Takahata et al., 2009; Watakabe et al., 2009; Yamamori, 2011). Whereas this experiment revealed the requirement for retinal activity in gene expression in V1, it has not been clear how the incoming visual inputs induce the expression of these genes.

Synaptic transmission triggers the expression of a group of genes, which play roles in neural plasticity, differentiation, proliferation etc. (Flavell and Greenberg, 2008; Fowler et al., 2011). Among these genes, immediate early genes (IEGs) including $c$-Fos and Zif268 are defined as the genes that are rapidly and transiently expressed within minutes to several hours from stimulus onset (Morgan et al., 1987; Sheng and Greenberg, 1990), and have been used as the markers for neural activities after sensory stimulation. Studies for how visual stimulation causes the induction of IEGs in the visual cortex have been also done in various mammalian species (Worley et al., 1991; Rosen et al., 1992; Chaudhuri and Cynader, 1993; Montero and Jian, 1995; Kaplan et al., 1996; Markstahler et al., 1998; Arckens et al., 2000; Soares et al., 2005; Warner et al., 2012). Previous studies in rodents demonstrated that visual stimulation induces the expressions of 
Zif268 and c-Fos proteins at the peak level within $1 \mathrm{~h}$ from stimulus onset (Worley et al., 1991; Zangenehpour and Chaudhuri, 2002), suggesting that input-driven gene activation in V1 reaches the maximum level within a short period of time. To our knowledge, however, there has been no information about visually evoked transcription in primate V1 during the early time course within $1 \mathrm{~h}$. Here, we designed a series of monocular visual stimulation experiments using adult marmosets, in order to dissect underlying molecular mechanisms upon changes of visual inputs in primates.

For our experiments, we selected common marmosets (Callithrix jacchus), a New World monkey, because of its size, ease of handling, and transgenic (Sasaki et al., 2009) and gene manipulation potentials (e.g., Watakabe et al., 2012). In the marmoset vision research, there have been debates whether ocular dominance columns (ODCs) exist (Sengpiel et al., 1996; Markstahler et al., 1998; Chappert-Piquemal et al., 2001; Roe et al., 2005) or not exist (Spatz, 1979, 1989; McLoughlin and Schiessl, 2006; Valverde Salzmann et al., 2012) in adult marmosets. With particular relevance to our study, Markstahler et al. (1998) reported columnar ZIF268 immunostaining in layer IVC $\beta 2 \mathrm{~h}$ after monocular visual stimulation following transient $(24 \mathrm{~h})$ monocular TTX injection, which they called "physiological ODCs." To investigate the visually evoked gene expression in primates, marmoset V1 is potentially a very good model.

In the present study, we modified the Markstahler's method (1998) to examine the mRNA expression of a set of activitydependent genes including $c$-FOS, ZIF268, and ARC in adult marmoset V1. Using this approach first, we demonstrated strong evidence for the segregation of right and left eye inputs in marmoset V1. Second, we have found that spontaneous activity has a critical role in the expression of HTR1B and HTR2A mRNAs in these primate-specific domains in an activity-dependent manner (Watakabe et al., 2009; Takahata et al., 2012). Last, we found that each of these activity-dependent genes revealed a different spatial and temporal time course upon visual stimulation. These results suggest that the regulation of each neuron in marmoset V1 is subjected to different regulation upon the change of activities from retina.

\section{MATERIALS AND METHODS ETHICS STATEMENT}

All the experiments were conducted in accordance with the guidelines of the National Institutes of Health, and the Ministry of Education, Culture, Sports, Science and Technology (MEXT) of Japan, and were approved by the Animal Care and Use Committee in the National Institutes of Natural Sciences. We made all efforts to minimize the number of animals used and their suffering.

\section{EXPERIMENTAL ANIMALS AND VISUAL MANIPULATION PROCEDURE}

A total of 16 adult common marmosets (Callithrix jacchus, 20-98 months, either sex, weighing 257-472 g) were used during the course of this study (11 marmosets among them were also used for other studies as well). These marmosets were kept under standard $12 \mathrm{~h}$ light: $12 \mathrm{~h}$ dark condition, until the manipulation was started. As shown in Figure 1, the visual manipulation typically started from the dark-reared (DR) condition, during which the marmosets were deprived of any possible light source. To achieve the DR condition, in addition to turning the room light off, we carefully covered the cage with a lightproof shield.

Five marmosets were visually intact and did not receive TTX injection. Three of them were used as the normal-reared (NR) condition marmosets: these marmosets were kept under $12 \mathrm{~h}$

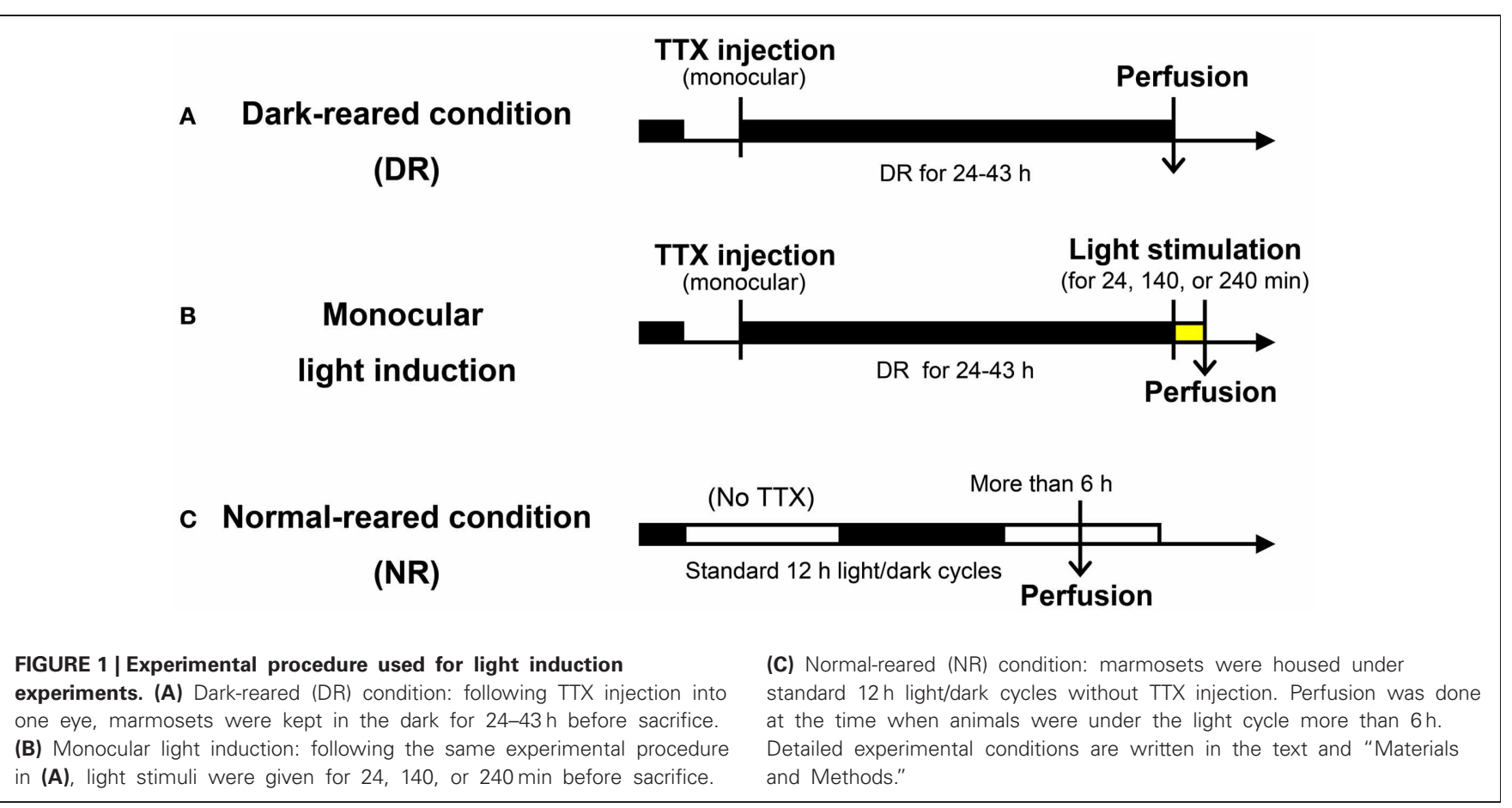


light: $12 \mathrm{~h}$ dark condition and sacrificed more than $6 \mathrm{~h}$ after the light cycle had started. Two of them were kept under the DR condition for one night and were exposed to a bright light from the front side of their cages for $2 \mathrm{~h}$ before sacrifice (NR 2h; control of TTX injection). The illuminance was 300 and $1500 \mathrm{~lx}$ under the NR condition and light stimulation, respectively. There was no object to hide from light sources in their cages.

Eleven other marmosets received monocular intravitreous injection of TTX to block retinal impulse activity. Under anesthesia of the ketamine and xylazine mixture $(25$ and $2.0 \mathrm{mg} / \mathrm{kg}$, respectively), $1.4-1.6 \mu \mathrm{l}$ of TTX ( $4.7 \mathrm{mM}$; Wako Pure Chemical Industries, Ltd., Osaka, Japan) was manually injected into the vitreous cavity of one eye using a Hamilton syringe. After injection, loss of the pupillary reflex in the injected eye was confirmed. After awakening from anesthesia, to completely reduce the transcription products already induced by normal breeding to basal level, we then kept the marmosets under the DR condition for 24-43 h prior to stimulation. Light stimulation was done by exposing to a bright light from the front side of the cages for $0,24,140$, and $240 \mathrm{~min}$ before being anesthetized for sacrifice. Information of the experimental procedures for each animal is summarized in Table 1.

\section{TISSUE PREPARATION}

The animals were sacrificed with overdose of sodium pentobarbital (100 mg/kg, intraperitoneally) following anesthesia of a mixture of ketamine and xylazine (30 and $2.7 \mathrm{mg} / \mathrm{kg}$ body weight, respectively; intramuscularly). Before the injection of sodium pentobarbital, the loss of the pupillary reflex in the TTX-injected eye was confirmed in all marmosets except the DR animals. After confirming that the marmosets were in deep anesthesia, they were perfused transcardially with $0.9 \% \mathrm{NaCl}$ containing $2 \mathrm{U} / \mathrm{mL}$ heparin, followed by fixation with $4 \%$ paraformaldehyde (PFA) in $0.1 \mathrm{M}$ phosphate buffer, $\mathrm{pH}$ 7.4. We carefully minimized the time period between anesthesia and infusion of PFA, particularly for the cases of short-term light induction. For example, in the case of 24-min-light stimulation, the marmosets started to receive 4\% PFA infusion within $35 \mathrm{~min}$ from the onset of light exposure. For the three marmosets with no visual stimulation (Table 1, DR_1,2,3), the anesthesia was induced in the dark room using night vision goggles, and the perfusion was performed under low light until PFA infusion started.

The brains were postfixed for $5 \mathrm{~h}$ at room temperature and then cryoprotected with $30 \%$ sucrose in $0.1 \mathrm{M}$ phosphate buffer at $4^{\circ} \mathrm{C}$. The tissue sections were made on a freezing microtome (20 $\mu \mathrm{m}$ thickness for IHC and double ISH; 20 to $25 \mu \mathrm{m}$ thickness for single ISH).

\section{SYNTHESIS OF RNA PROBES}

The probes used for ISH experiments were PCR-cloned by using the primers listed in Table 2. These primers were designed based on the marmoset sequences, deposited on Ensemble (http://www.ensembl.org) (Flicek et al., 2012). The cDNA fragments were obtained by RT-PCR using the total RNA purified from the occipital part of the marmoset neocortex. After subcloning, the sequences were checked using the BLAT alignment tool (Kent, 2002) for the marmoset in the UCSC Genome Browser database (http://genome.ucsc.edu/) (Kent et al., 2002). The digoxygenin (DIG)- and fluorescein isothiocyanate (FITC)labeled riboprobes were produced using these plasmids as templates for in vitro transcription. For the detection of ZIF268, HTR1B, HTR2A, and VGluT1 mRNAs, we used the probes

Table 1 | Marmosets used for monocular visual stimulation experiments.

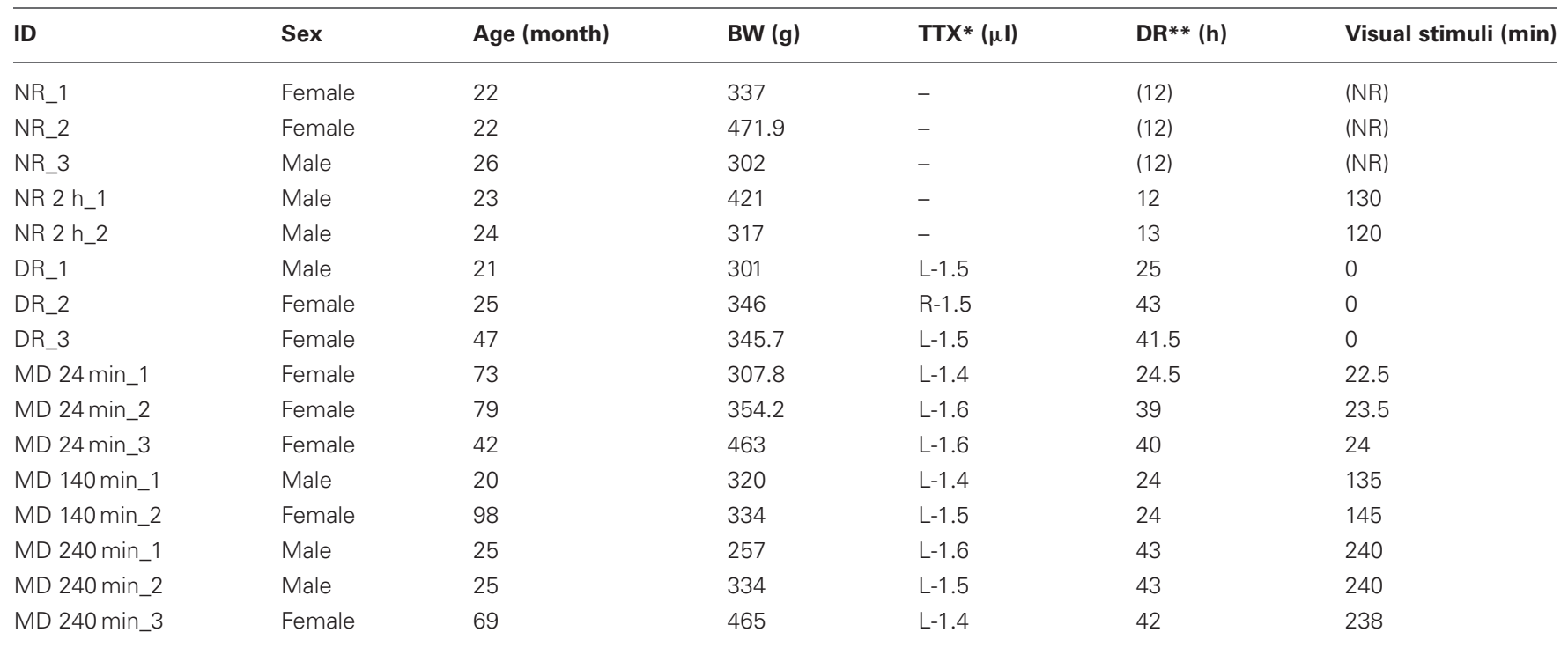

${ }^{*} L$, left eye; $R$, right eye; -, no treatment.

**Marmosets were kept under the DR condition for the indicated length of time prior to stimulation. NR marmosets were reared under standard $12 \mathrm{~h}$ light: $12 \mathrm{~h}$ dark condition. See "Materials and Methods" for details. 
Table 2 | ISH probes used in current study.

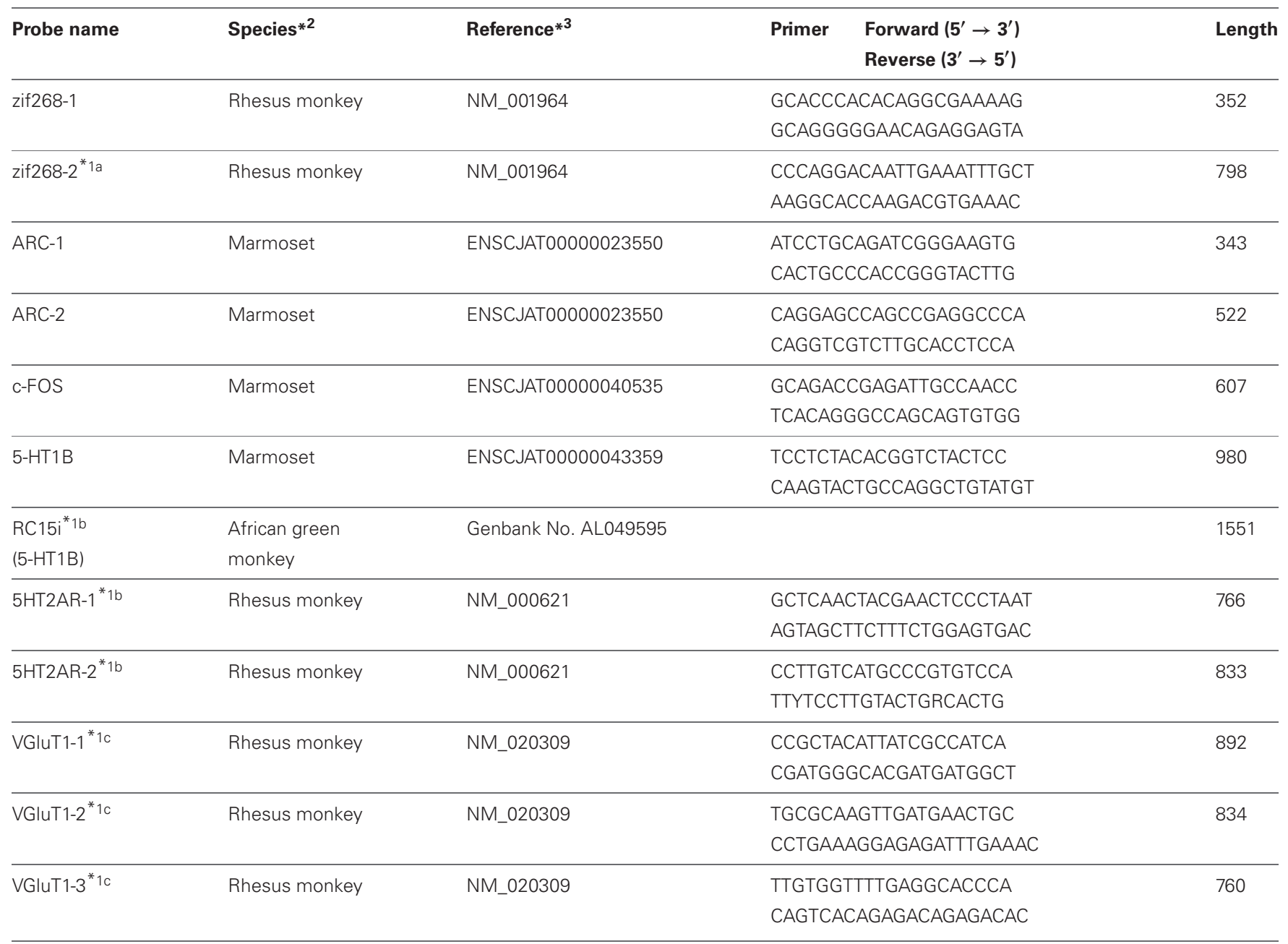

*1: ISH probes used in previous works (a, Takahata et al., 2008; b, Watakabe et al., 2009; c, Komatsu et al., 2005).

${ }^{*}$ 2: Species of the cDNA cloned in each probe.

*3: Reference sequences of marmoset, macaque, or human used to design PCR primers.

previously used for monkey ISH (Komatsu et al., 2005; Takahata et al., 2008; Watakabe et al., 2009). We also conducted ISH for the sense probes of each gene to confirm the specificity of the antisense probes (data not shown).

\section{In situ HYBRIDIZATION}

Single-colored ISH was carried out as described previously with minor modifications (Liang et al., 2000; Komatsu et al., 2005). Free-floating sections were treated with $5 \mu \mathrm{g} / \mathrm{mL}$ proteinase $\mathrm{K}$ for $30 \mathrm{~min}$ at $37^{\circ} \mathrm{C}$. After acetylation, the sections were incubated in a hybridization buffer $[5 \times$ standard saline citrate (SSC), 2\% blocking reagent (Roche Diagnostics, Basel, Switzerland), 50\% formamide, $0.1 \%$ N-lauroylsarcosine (NLS), $0.1 \%$ SDS ] containing $0.5 \mu \mathrm{g} / \mathrm{mL}$ DIG-labeled riboprobes at $60-65^{\circ} \mathrm{C}$. Hybridized sections were washed twice in $2 \times \mathrm{SSC} / 50 \%$ formamide/ $0.1 \%$ NLS for $20 \mathrm{~min}$ at the same temperature for hybridization, then treated at $37^{\circ} \mathrm{C}$ in RNase buffer $[10 \mathrm{mM}$ Tris-HCl, pH 8.0, 1 mM ethylenediaminetetraacetic acid (EDTA),
$500 \mathrm{mM} \mathrm{NaCl}$ ] containing $20 \mu \mathrm{g} / \mathrm{mL}$ RNase A (Sigma-Aldrich, St. Louis, MO) for $30 \mathrm{~min}$. The sections were further washed twice at $37^{\circ} \mathrm{C}$ in $2 \times \mathrm{SSC} / 0.1 \% \mathrm{NLS}$, and then twice in $0.2 \times$ SSC/0.1\% NLS. Hybridization signals were visualized by alkaline phosphatase immunohistochemistry followed by nitro-blue tetrazolium/5-bromo-4-chloro-3-indolylphosphate (NBT/BCIP) detection (Roche Diagnostics, Tokyo, Japan).

Fluorescence double-colored ISH was performed using DIGand FITC-labeled riboprobes as described previously (Komatsu et al., 2005; Watakabe et al., 2010). The hybridization was carried out as described above, except that both DIG- and FITC-labeled riboprobes were used for the hybridization. After blocking in $1 \%$ blocking buffer (Roche Diagnostics) for $1 \mathrm{~h}$, DIG- and FITC-labeled riboprobes were detected in two different ways. For the detection of the FITC probes, the sections were incubated with an anti-FITC antibody conjugated with horseradish peroxidase (1:5000 in the blocking buffer; Jackson ImmunoResearch Laboratories, West Grove, PA; \#200-032-037) 
for $2-4 \mathrm{~h}$ at room temperature. After washing in TNT $(0.1 \mathrm{M}$ Tris- $\mathrm{HCl}, \mathrm{pH} 7.5,0.15 \mathrm{M} \mathrm{NaCl}, 0.1 \%$ Tween 20) three times for $15 \mathrm{~min}$, the sections were treated with 1:100-diluted TSAPlus reagents for $30 \mathrm{~min}$ in accordance with the manufacturer's instruction (Perkin-Elmer, Wellesley, MA), and the FITC signals were converted to dinitrophenyl (DNP) signals. After washing in TNT three times for $10 \mathrm{~min}$, the sections were incubated for $2-4 \mathrm{~h}$ at room temperature or overnight at $4{ }^{\circ} \mathrm{C}$ with an anti-DNP antibody conjugated with Alexa 488 [1:500, Molecular Probes (Life Technologies Corporation), Carlsbad, CA] in 1\% blocking buffer for the fluorescence detection of the DNP signals. At this point, an anti-DIG antibody conjugated with alkaline phosphatase (1:1000, Roche Diagnostics) was included in the incubation, for the detection of the DIG probes. The sections were washed thrice in TNT, once in TS 8.0 (0.1 M Tris- $\mathrm{HCl}, \mathrm{pH} 8.0$, $0.1 \mathrm{M} \mathrm{NaCl}, 50 \mathrm{mM} \mathrm{MgCl}_{2}$ ), and the alkaline phosphatase activity was detected using an HNPP fluorescence detection set (Roche Diagnostics) in accordance with the manufacturer's instruction. The incubation for this substrate was carried out for $40 \mathrm{~min}$ and stopped by washing in phosphate buffered saline (PBS) containing $0.5 \mathrm{mM}$ EDTA. The sections were then counterstained with Hoechst 30442 (Molecular Probes) diluted in PBS to 1:1000 for $5 \mathrm{~min}$.

\section{IMMUNOHISTOCHEMISTRY}

We used anti-c-Fos polyclonal rabbit IgG antibody (Santa Cruz Biotechnology, Santa Cruz, CA; sc-52), which was raised against a peptide mapping at the $\mathrm{N}$-terminus of $\mathrm{c}$-FOS of human origin, for c-Fos immunoreactivity. We previously confirmed the specificity and used this antibody in rats (Sakata et al., 2002; Hirokawa et al., 2008). For marmoset c-FOS IHC, the monocularly deprived and normal columns in V1 showed clear contrast between two types of columns as shown in the result figures, which confirmed the specificity as internal controls.

For immunoperoxidase reaction, the free-floating sections were incubated in Tris-buffered saline (TBS) containing 1\% $\mathrm{H}_{2} \mathrm{O}_{2}$ for $30 \mathrm{~min}$ at room temperature. After rinsing in TBS, the sections were immersed for $1 \mathrm{~h}$ at room temperature in the blocking buffer (5\% bovine serum albumin, $0.1 \%$ Triton $\mathrm{X}-100$, and $4 \%$ normal goat serum in TBS). Reaction with an anti-c-Fos antibody (1:1200) was performed in the blocking buffer overnight at $4^{\circ} \mathrm{C}$. Following incubation with an biotinylated donkey anti-rabbit IgG (1:4000; Jackson ImmunoResearch Laboratories) in the blocking buffer for $2 \mathrm{~h}$ at room temperature, the sections were processed with an avidin-biotinylated horseradish peroxidase complex (1:200; Vectastain ABC Elite kit, Vector Laboratories, Burlingame, CA) in TBS at room temperature for $1 \mathrm{~h}$ and the immunoreaction was visualized by staining with nickel-enhanced coloring solution $[0.2 \mathrm{mg} / \mathrm{mL}$ diaminobenzidine (DAB), $0.03 \% \mathrm{H}_{2} \mathrm{O}_{2}, 0.03 \%$ nickel chloride in TBS].

\section{DATA ANALYSIS}

In this study, we adopted Brodmann's nomenclature for the V1 layering. We determined the layer positions based on Nissl staining of the adjacent section. To identify the precise lamina positions, we also performed double ISH of the genes of interest with several layer marker genes, such as Nurr1 (Nr4a2), Neurofilament (NEFM), ER81 (ETV1), and VGluT1 (Watakabe et al., 2007). In this paper, we designated the ODCs as the activeeye and the inactive-eye columns that received projection from the intact and the TTX-injected eyes, respectively.

The images for ISH and IHC were obtained using a digital color camera DP70 (Olympus, Tokyo, Japan) attached to a BX51 microscope (Olympus). All the figures obtained in the ISH and the IHC experiments were adjusted for appropriate contrast using Adobe Photoshop (Adobe Systems, San Jose, CA). Although the sections for ISH shrank, the scale bars in the figures show the size of mounted sections, which were not adjusted for shrinkage.

The laminar profiles shown in Figures 3, 6 were quantified by measuring the integrated optical densities (IODs) of the ISH signals in the designated layers as follows. First, we obtained columnar images of active-eye and inactive-eye columns, which contained from layer I to WM vertically, and pasted all images measuring IODs in one canvas for each gene using Adobe Photoshop. We obtained the layer values for an active-eye column and for an inactive-eye column per section. To obtain the average signal intensity, five or six sections from two to three different marmosets in each time point (Table 1). Second, two vertical lines were set within the active- or inactive-eye column to obtain the line profile using the "line profile (thick vert)" menu of ImagePro Plus. In this menu, the 8-bit gray-scale values of the pixels at each vertical position were averaged to determine the optical density at that position. Third, this line profile was referenced to the cortical layers determined as described above. Fourth, a portion (30 pixel height) of each layer (or sublayer) was set as the ROI for IOD measurement. That is, the OD values at particular lamina positions were integrated as the "signal intensity" of this layer. Signal to noise ratio of ISH signal was high enough so that the background level can be negligible. In order to combine data from multiple samples we carefully perform the tissue processing (e.g., storage of samples, pegged coloring time) and carried out ISH of cortical tissues of different animals at the same condition. Within a range of difference in the length of the darkrearing time in the current study, the expression profiles were confirmed to be similar among the samples obtained at the same time point.

\section{RESULTS}

\section{FUNCTIONAL ODCS IN V1 OF ADULT MARMOSETS THROUGHOUT LAYERS II-VI VISUALIZED BY MONOCULAR LIGHT INDUCTION EXPERIMENT}

To investigate the time course of activity-dependent gene expression in V1, we carried out a series of light induction experiments in monocularly inactivated marmosets. As shown in Figure 1, following intravitreous injection of TTX to monocularly block retinal activity, marmosets were kept under the DR condition for one or two days to reduce the level of activity-dependent gene expression to the basal level. We then exposed them to a bright light from the front side of the cages for different time periods before sacrifice. In this way, we were able to objectively compare the expression patterns between active- and inactive-eye columns. 
Although there had been controversy with regard to the presence of ODCs in marmosets, we always observed stripe patterns of expression for the activity-dependent genes as previously observed in macaques (Takahata et al., 2009; Watakabe et al., 2009) (Figure 2). Consistent with the previous report (Markstahler et al., 1998), the active-eye columns were visualized by ISH for ZIF268 in the marmoset visual cortex (Figure 2A). Similar stripe patterns were observed for two other IEGs, $A R C$ and $c$-FOS, as well (Figures $\mathbf{2 B}, \mathbf{C}$ ). In this series of experiments, all monocularly inactivated marmosets showed clear stripe signals of IEGs through layers II-VI without exception. The distinction between active- and inactive-eye columns was less conspicuous in layers outside layer IVC $\beta$, suggesting relatively less segregation of inputs in other layers. We also confirmed that HTR $1 B$ and HTR2A mRNAs exhibit stripe patterns in layer IVC in these monocularly inactivated marmosets (Figures 2D,E). Figure 2G shows the ISH of ZIF268 in the cortical section obtained from a marmoset which was received $2 \mathrm{~h}$-light stimulation without monocular TTX injection (NR $2 \mathrm{~h}$ ). Note that there is no stripe pattern in any layers in V1 (Figure 2G). These findings demonstrate the clear segregation of ODCs in adult marmoset V1.

\section{DIFFERENTIAL REQUIREMENTS FOR VISUAL INPUTS IN THE INDUCTIONS OF HTR1B AND HTR2A GENES}

As previously reported (Takahata et al., 2012), both HTR1B and HTR2A mRNAs were preferentially expressed in marmoset V1 (Figure 3A). The expression of HTR1B mRNA was mostly

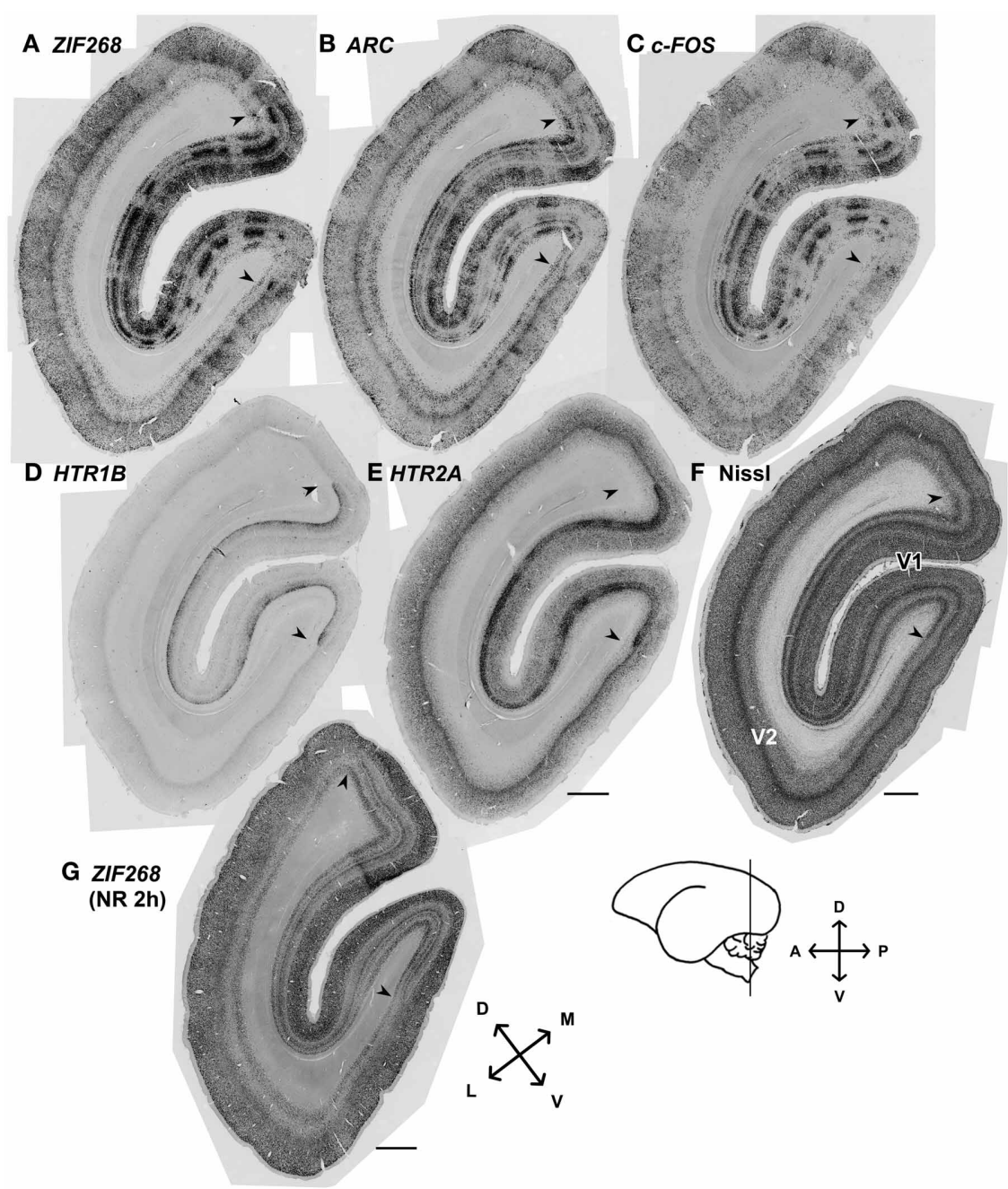

FIGURE 2 | mRNA expression patterns of five activity-dependent genes induced by monocular light stimulation in visual cortices of adult marmosets. (A-E) mRNA expression patterns for activity-dependent genes we examined in the visual cortex 24 min after light stimulation: (A) ZIF268, (B) ARC, (C) C-FOS, (D) HTR1B, and (E) HTR2A. Columnar patterns within V1 indicate ocular dominance columns. (F) Cortical section stained for Nissl substance. Adjacent sections were analyzed in (A-F). Magnified images at other time points were shown in Figures 3, 5. (G) The mRNA expression pattern for ZIF268 in the cortical section obtained from a marmoset which was received $2 \mathrm{~h}$-light stimulation without monocular TTX injection (NR $2 \mathrm{~h}$ ). No stripe pattern was observed in any layers of V1. Arrowheads indicate V1N2 boundaries. Cortical sections were prepared from the position depicted by the line on the brain diagram. D, dorsal; $V$, ventral; $A$, anterior; $P$, posterior; $L$, lateral; and $M$, median. Scale bars: $1 \mathrm{~mm}$. 
A

\section{HTR1B}

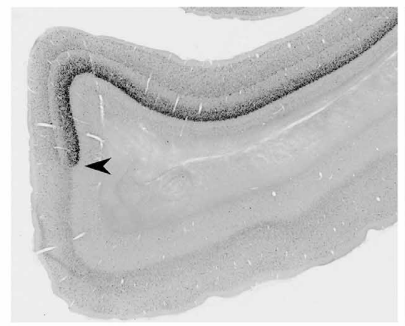

HTR2A

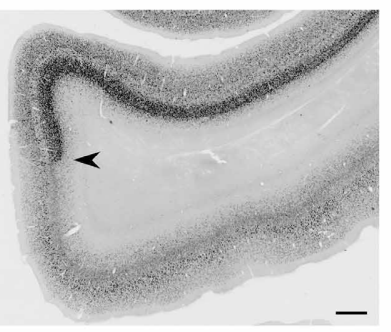

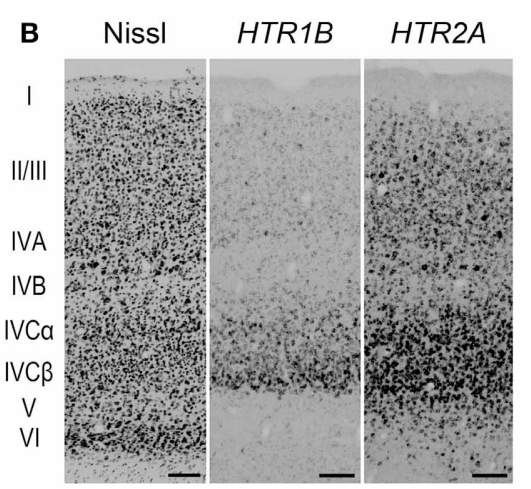

$240 \min$

$140 \min$

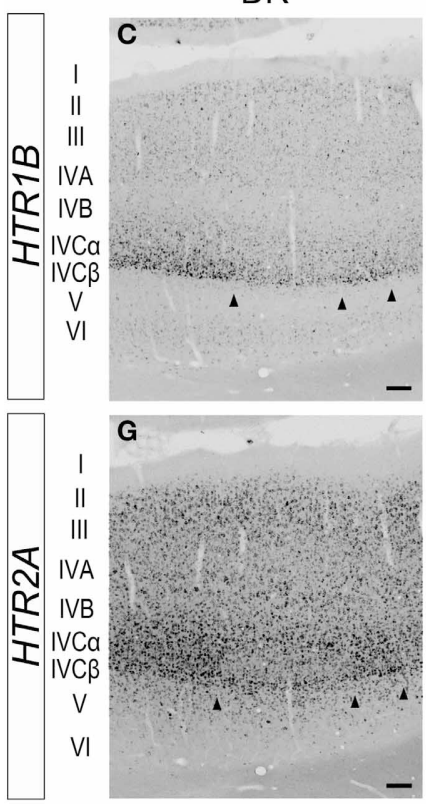

$24 \mathrm{~min}$

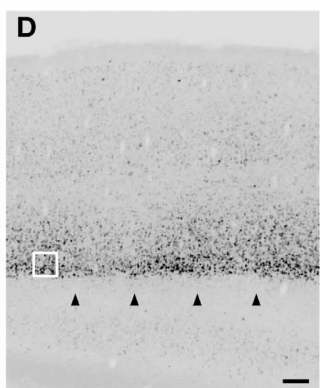

E

$\mathbf{F}$
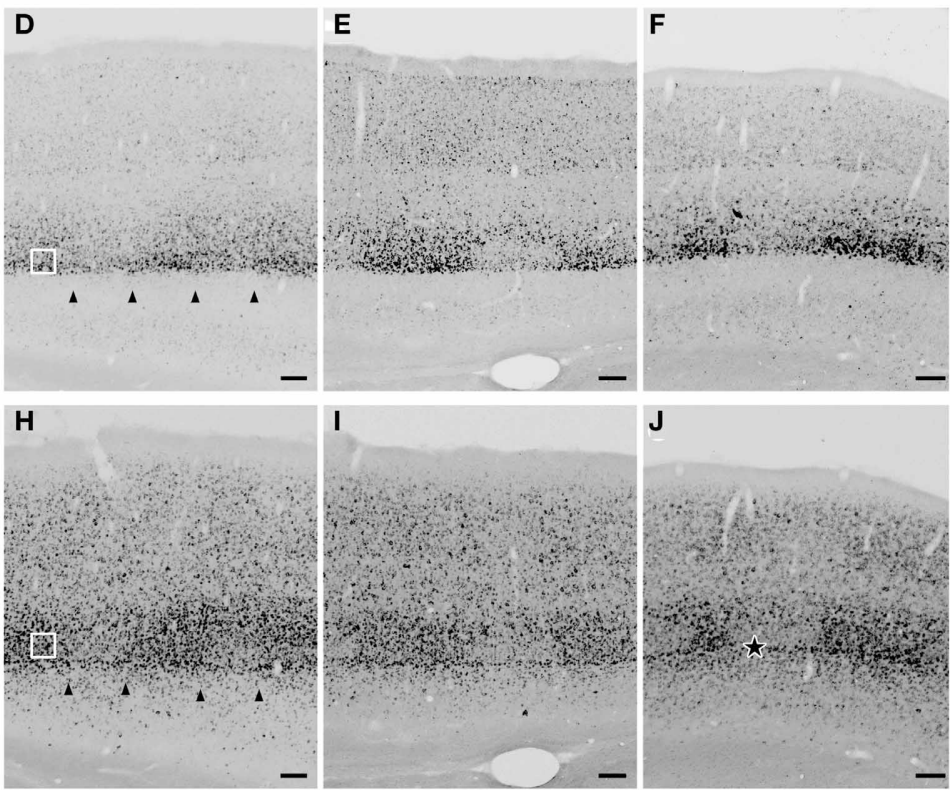

$\mathbf{J}$

$\mathbf{K}$

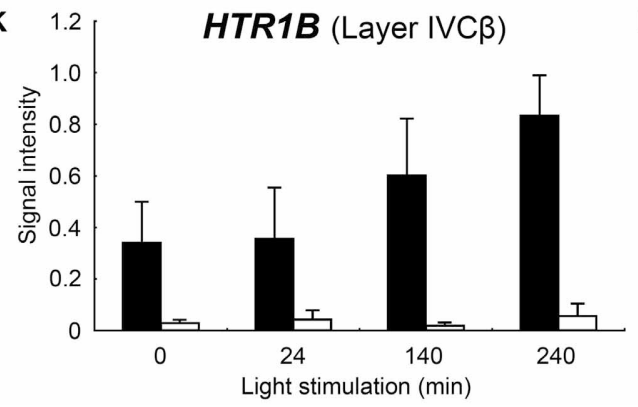

L ${ }^{1.2} \mid$ HTR2A (Layer IVC $\beta$ )

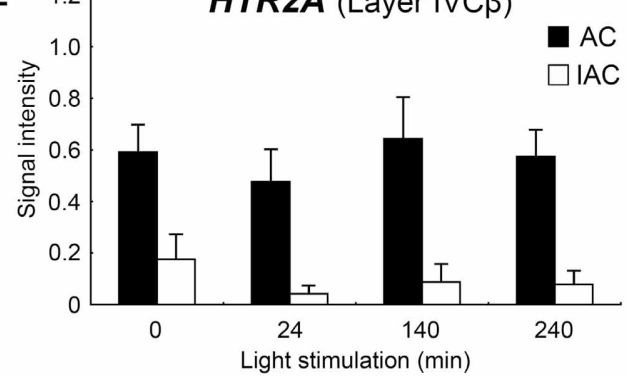

FIGURE 3 | Expressions of HTR1B and HTR2A mRNAs in marmoset V1. (A) mRNA expressions of HTR1B and HTR2A in the visual cortex of the normal-reared (NR) marmoset as in Figure 1C. Arrowheads indicate the V1N2 boundaries. Note the area-specific expression pattern of HTR1B and HTR2A mRNAs in V1. Scale bar: $500 \mu \mathrm{m}$. (B) Laminar distributions of HTR1B and HTR2A mRNAs in V1. Both genes were higher expressed in layer IVC. (C-J) ISH signals of HTR1B (C-F) and HTR2A (G-J) mRNAs in V1 of monocular inactivated marmosets. Twenty-four minutes (D,H), $140 \mathrm{~min}$ (E,I), and $240 \mathrm{~min}(\mathbf{F}, \mathbf{J})$ after monocular light induction as in Figure 1B. (C,G) Dark-reared animals (DR) as in Figure 1A. The filled star in panel (J) indicates the position of sublayer where HTR2A mRNA was constantly expressed across ODCs. Arrowheads indicate boundaries of ODCs, which were demarcated on the basis of the pattern of ZIF268 mRNA in the adjacent sections. Open squares in panels $(\mathbf{D}, \mathbf{H})$ indicate the regions of layer IVC $\beta$ isolated for quantification analysis as examples. The regions of other time points are also taken at similar layer positions for quantification analysis in (K) and (L). Scale bars: $100 \mu \mathrm{m}$. (K,L) Quantification of mRNA signal levels of HTR1B (K) and HTR2A (L) in layer IVC $\beta$ of V1 for each time point. Filled bars, active-eye columns (AC); open bars, inactive-eye columns (IAC). For this calculation, five sections (for DR and $140 \mathrm{~min}$ ) and six sections (for 24 and $240 \mathrm{~min}$ ) were obtained from two or three marmosets in each time point (see Table 1). Error bars show SD. 
confined to layer IVC (particularly strong in layer IVC $\beta$ ) and weakly observed in layers II, III, and IVA (Figure 3B). HTR2A mRNA was expressed in layers II-V, with higher expression in layer IVC (Figure 3B). Next, we examined the time course of HTR $1 B$ and HTR2A gene expressions in response to the visual stimulation. In regard to $H T R 1 B$ and $H T R 2 A$, the effect of monocular inactivation by TTX was observed in layer IVC. HTR1B mRNA was expressed at a low level under the DR condition and gradually increased its expression level in proportion to the length of visual stimuli (Figures 3C-F). As quantified in Figure 3K, although the $H T R 1 B$ mRNA level did not significantly change during the first $24 \mathrm{~min}$, it increased from 140 to $240 \mathrm{~min}$. The expression levels of HTR2A mRNA, on the other hand, were similar within the stimulus conditions including the DR (Figures 3G-J). In our experiments, we did not find any significant increase in signal intensities for HTR2A mRNA, during visual stimulation within $240 \mathrm{~min}$ (Figure 3L), indicating that HTR2A mRNA was expressed at a certain level without light stimulation. Note that blocking the retinal activity by TTX reduced the level of both $H T R 1 B$ and HTR2A mRNAs even under the DR condition (Figures $\mathbf{3 C}, \mathbf{G}$ ). This observation suggested that spontaneous retinal activity sustained a level of HTR $1 B$ and HTR2A mRNA expression, irrespective of light stimulation. Thus, a series of monocular light induction experiment performed here revealed: first, the difference of HTR1B and HTR2A mRNA expressions in terms of their requirement for visual inputs to achieve the maximum level of expression, and second, the requirement for spontaneous retinal activities in their mRNA expression.
The expression profiles of HTR $1 B$ and HTR2A mRNAs also revealed a characteristic sublamina configuration of marmoset V1, which may be difficult to see by other methods. At the border between layers IVC $\beta$ and V, we were consistently able to observe a narrow band of HTR2A mRNA that was present across the active- and inactive-eye columns (filled star, Figure 3J and at a similar position through the panels of $\mathbf{G}-\mathbf{I}$ ). To examine whether this sublayer belongs to layer IVC or V, we performed the double ISH of HTR1B and HTR2A. White arrows in Figure 4A indicate the sublayer where HTR2A mRNA was constantly expressed across ODCs. In magnified images of Figure 4B, arrowheads indicate the neurons in this sublayer, and HTR $1 B$ mRNA coexpressed in these neurons, suggesting this sublayer is a part of layer IVC. Although these HTR2A-positive sublayer neurons were excitatory neurons (white arrow, Figure 4C), the expression of HTR2A mRNA was not activity-dependent. These results indicate the different regulation of gene expression between HTR1B and HTR2A genes in response to retinal activity in this sublayer.

\section{DIFFERENT TIME COURSE OF IEG EXPRESSION IN LAYERS OF V1}

The slow time course of HTR1B induction led us to examine a faster time course of the mRNA expression of $c$-FOS, ARC, and ZIF268 (Flavell and Greenberg, 2008; Fowler et al., 2011). Figure 5 shows laminar distributions of the mRNA expression of these IEGs. Under the DR condition, ZIF268 mRNA was expressed at a very low level in layer IVC $\beta$ of active-eye columns (Figure 5B), suggesting that spontaneous inputs from normal retina induce ZIF268 mRNA expression in layer IVC $\beta$ of V1. ARC
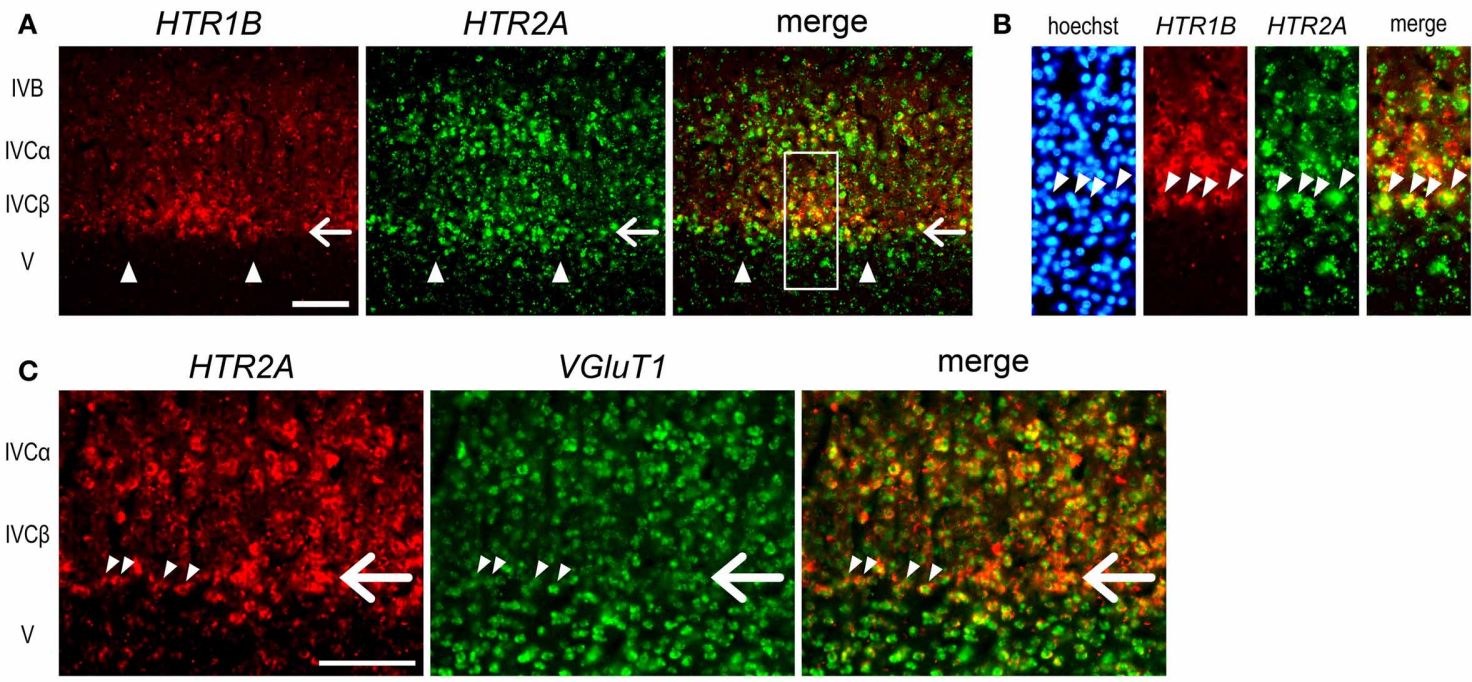

FIGURE 4 | Double ISH of HTR1B and HTR2A in V1 of monocularly stimulated marmosets. (A) Double ISH of HTR1B (red) and HTR2A (green) mRNAs 240 min after visual stimulation. HTR1B and HTR2A mRNAs were coexpressed in most of the same neurons in active-eye columns of layer IVC in V1. White arrows indicate the sublayer where HTR2A mRNA was constantly expressed regardless retinal activity. This is the same sublayer which is indicated by a filled asterisk in Figure 3J. Arrowheads indicate the boundaries of ODCs. (B) Magnified images of the region indicated by open box in (A). Arrowheads indicate the neurons of the HTR2A-positive sublayer These neurons correspond to the lower end of HTR1B-positive neurons, suggesting that this sublayer is a part of layer IV and that there are difference in activity-dependency of mRNA expression between HTR1B and HTR2A. (C) Double ISH of HTR2A (red) and VGluT1 (green) mRNAs 140 min after visual stimulation. White arrows indicate the similar sublayer in (A). Arrowheads indicate the neurons in this sublayer. VGluT1 mRNA was also expressed in these neurons. Scale bars: $100 \mu \mathrm{m}$. 


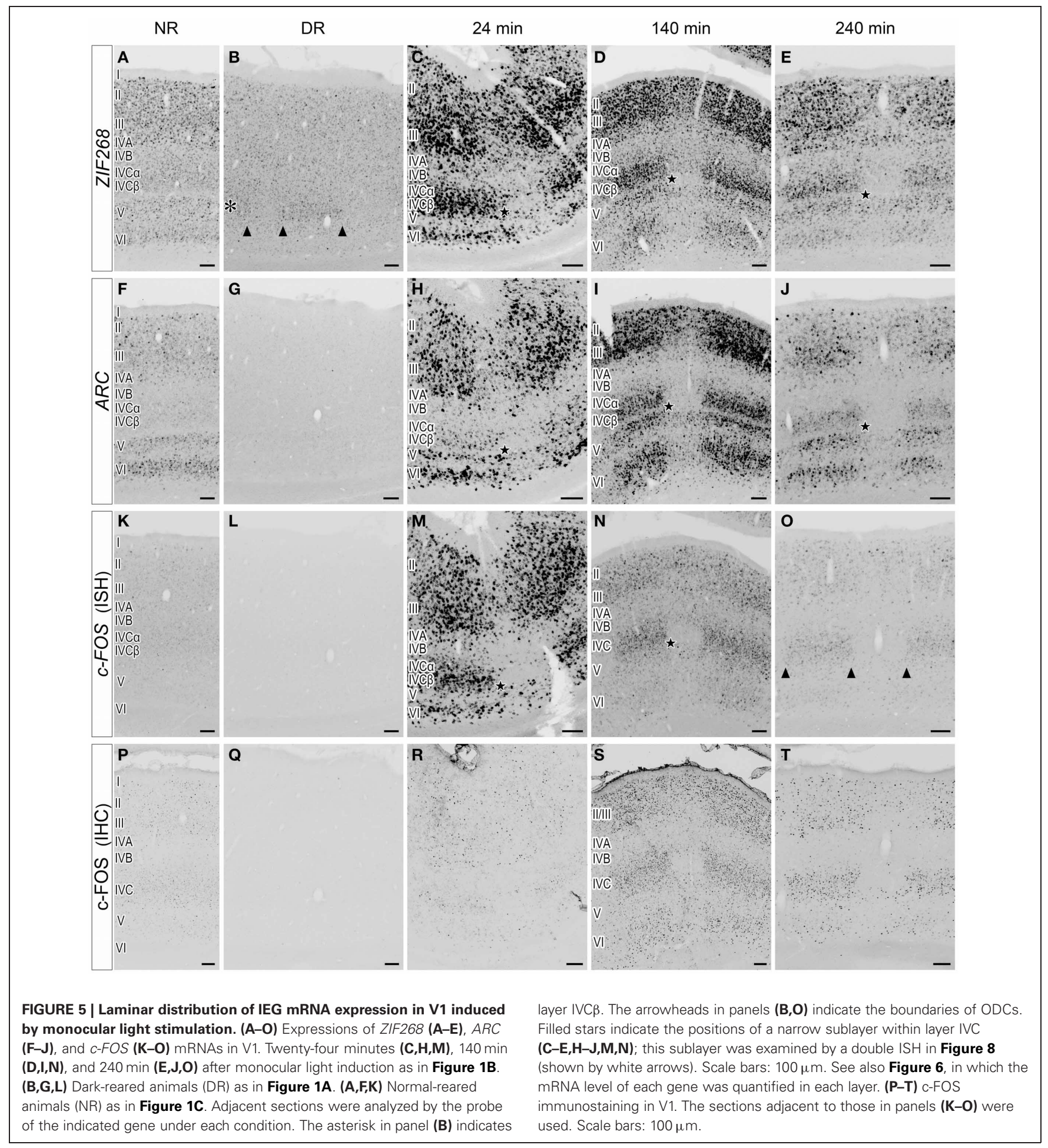

and $c-F O S$ mRNAs were totally absent under the DR condition (Figures 5G,L), indicating that visual stimulation is required to activate the expression of these two IEGs.

Upon light stimulation, the expression of all the IEGs was rapidly induced across layers in V1. Interestingly, the time course of expression was quite different among layers, especially in layers
III, IVC, and VI, signal intensities of ISH were rapidly changed within short term (quantified data in Figure 6). For example, $A R C$ mRNA was abundantly expressed in layers II, III, V, and VI within $24 \mathrm{~min}$, but very faint in layer IVC at this time point (about $10 \%$ against its peak we examined) (Figure 5H). After $140 \mathrm{~min}$, $A R C$ mRNA expression was observed in layers II, III, IVC, V, and 


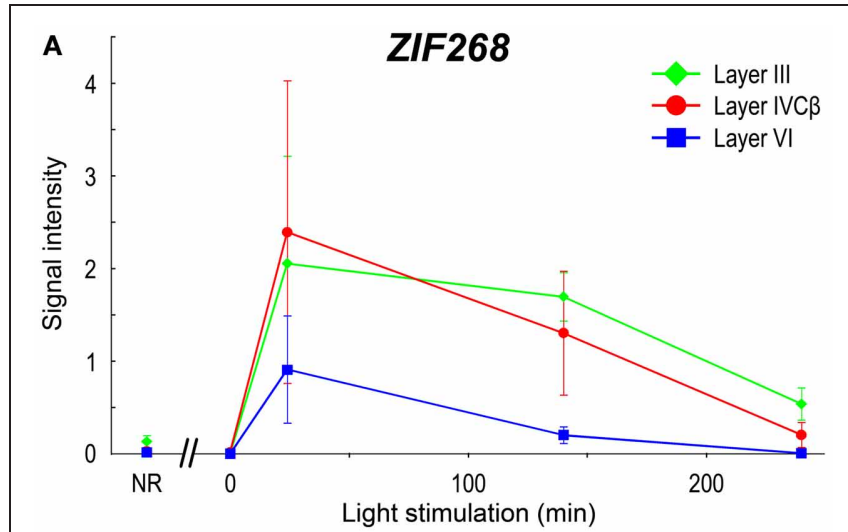

B
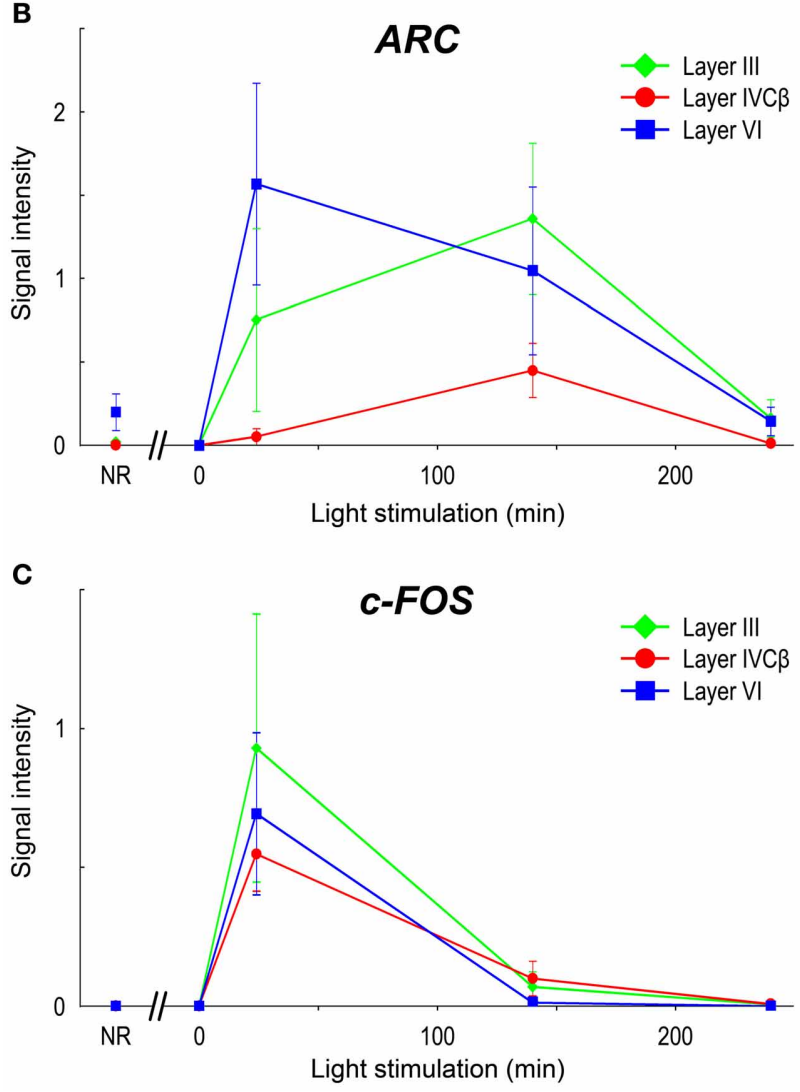

FIGURE 6 | mRNA levels of IEGs in marmoset V1 induced by monocular light stimulation. Signal intensities of ISH of IEGs in layers III, IVC $\beta$, and $\mathrm{VI}$ in $\mathrm{V} 1$ are shown: (A) ZIF268, (B) ARC, and (C) C-FOS. To quantify laminar distribution, signal intensities of ISH were calculated under each stimulus time in each layer (or sublayer) (see "Materials and Methods" for details). NR: mRNA levels in V1 of NR marmosets. For this calculation, five or six sections were obtained from two or three marmosets in each time point (see Table 1). The plots for different layers are indicated by colors (green: layer III; red: layer IVC $\beta$; blue: layer VI). Error bars show SD.

$\mathrm{VI}$ at the peak of the expression (Figure 5I). After $240 \mathrm{~min}$ the expression level of ARC mRNA decreased in all layers (2.4-12\% against its peak of each layer), particularly pronounced in the upper layers (Figure 5J). As shown in Figure 6B, the peak of $A R C$ mRNA expression in layers III and IVC was at $140 \mathrm{~min}$, whereas that in layer VI was at $24 \mathrm{~min}$. Under the NR condition (i.e., marmosets exposed to light over $6 \mathrm{~h}$ and without any TTX injection), the signals of $A R C$ mRNA were observed in layers II, III, V, and VI, but not in layer IVC (Figure 5F).

In the case of $c$-FOS, its mRNA was expressed in layers II, III, IVA, IVC, V, and VI within $24 \mathrm{~min}$ and then rapidly decreased and almost disappeared after $240 \mathrm{~min}$ (Figures 5M-O). The expression level of $c$-FOS mRNA was strongest at $24 \mathrm{~min}$ among the time points examined and rapidly decreased less than $1.8-18 \%$ against its peaks in all layers within $140 \mathrm{~min}$ (Figure 6C). Note that mRNA expression in layer VI had almost gone within $140 \mathrm{~min}$ even though remained in other layers (Figure $5 \mathbf{N}$ ), suggesting that the reduction of mRNA was also differently regulated in each layer. $c$-FOS mRNA was barely observed under the NR condition in all layers (Figure 5K).

Although the laminar distribution of ZIF268 mRNA was similar to that of $c$-FOS mRNA (Figures 5C-E), the time course of ZIF268 mRNA expression was different. As shown in Figure 6A, the mRNA expression of ZIF268 was rapidly induced in all layers at $24 \mathrm{~min}$ at the peak level. ZIF268 mRNA sustained relatively high expression level at $140 \mathrm{~min}(82.5,54.5$, and $22 \%$ against its peak levels in layers III, IVC $\beta$, and VI, respectively). A certain level of mRNA expression was observed in layers II-VI even under the NR condition (Figure 5A). In contrast to ARC mRNA, ZIF268 mRNA was expressed stronger in the upper layers under the NR condition.

The time course of expression is different for mRNA and protein (Zangenehpour and Chaudhuri, 2002; Kovacs, 2008). Using the anti-c-FOS antibody, we compared the difference between mRNA and protein expressions. At $24 \mathrm{~min}$, c-FOS immunoreactivity was sparsely observed in layer II/III, in contrast to strong expression of $c$-FOS mRNA at the same time point (Figures 5M,R). The c-FOS immunostaining signal became abundantly observed at $140 \mathrm{~min}$ (Figure 5S) and was still present at $240 \mathrm{~min}$, at which point $c$-FOS mRNA was almost gone (Figures 50,T). Under the NR condition, however, c-FOS immunostaining signals became very weak (Figure 5P), indicating that the protein expression followed mRNA expression with a certain time lag in the same cells in marmoset V1.

\section{HETEROGENEITY OF ACTIVITY-DEPENDENT REGULATIONS SIMULTANEOUSLY OCCURRED IN THE SAME NEURON}

Considering gene-specific differences of mRNA expressions, we wanted to know whether these mRNAs are expressed within the same or different neurons. To examine this, we carried out double ISH of these three IEG mRNAs. At $24 \mathrm{~min}$, ZIF268 and cFOS mRNAs were coexpressed in almost all neurons (Figure 7A), indicating that these IEGs might be induced by a similar regulatory mechanism. On the other hand, induction of $A R C$ and $c$-FOS mRNAs was not always similar in all layers. For example, at $24 \mathrm{~min}$, both mRNAs were coexpressed in almost neurons in layer VI, although $A R C$ mRNA was not yet expressed in layer IVC (Figure 7B). At $140 \mathrm{~min}$, however, $A R C$ and c-FOS mRNAs were mostly coexpressed in layer IVC (Figure 7B), suggesting that these IEGs were induced in the same neurons, but the timing of $A R C$ induction was different between layers IVC and VI. Collectively, these data indicate that parallel transcriptional 


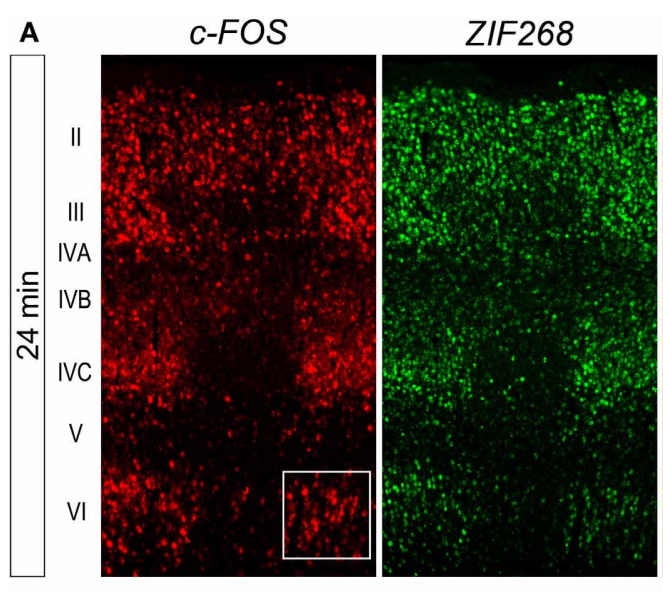

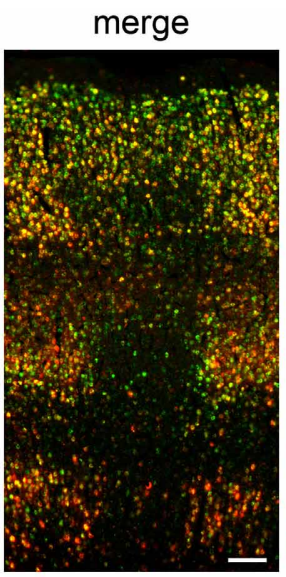

c-FOS

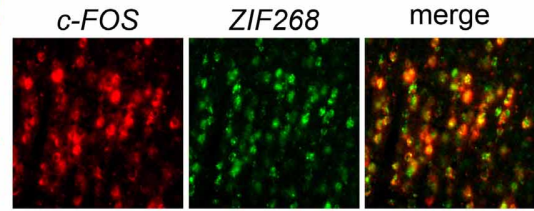

merge
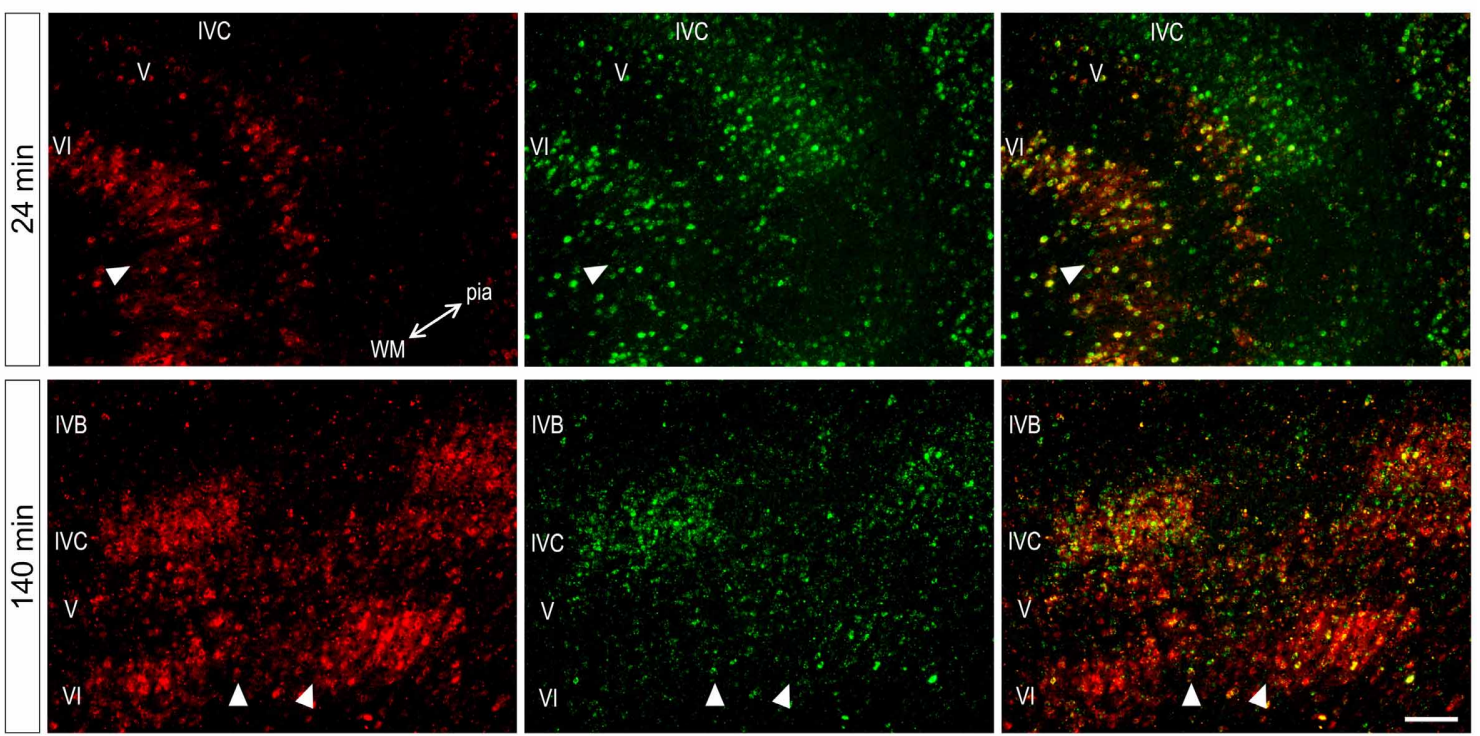

FIGURE 7|Double ISH of IEGs in V1 of monocularly stimulated marmosets. (A) Double ISH of c-FOS (red, left) and ZIF268 (green, middle) mRNAs $24 \mathrm{~min}$ after light stimulation. C-FOS and ZIF268 mRNAs were coexpressed in most neurons throughout layers.

(B) Double ISH of ARC (red, left) and c-FOS (green, middle) mRNAs in $\mathrm{V} 1 . A R C$ and $c$-FOS mRNAs were coexpressed in most neurons in the layers when they were expressed at each time point. The two-way arrow indicates the direction of lamination from pial (pia) to white matters (WM). Arrowheads indicate the boundaries of ODCs. Scale bars: $100 \mu \mathrm{m}$. regulations of these three IEGs take place in the same neuron upon the same stimulation in the marmoset primary visual cortex.

In this series of monocular visual stimulation experiments, we were able to reveal the existence of a sublayer of layer IV that exhibits a unique pattern of gene expression. A previous study showed the narrow (thin) pale-staining rim below the strong ZIF268 signals in layer IVC in marmoset V1 (Markstahler et al., 1998). From its position, this sublayer is considered as equivalent to the blank sublayer of ZIF268 mRNA observed at $140 \mathrm{~min}$ after light induction (showed by the filled star in Figure 5D). However, the ZIF268 ISH at $24 \mathrm{~min}$ did not show such a blank layer at the equivalent lamina position (showed by the filled star in Figure 5C). As described above, HTR2A also exhibited a narrow sublayer around this lamina position (Figures 3, 4). To identify this narrow sublayer in more detail, we performed double ISH of ZIF268 and HTR2A mRNAs in the cortical sections of 24- and 140-min-stimulated marmosets (Figure 8). We found that ZIF268 mRNA lacked the expression in the same sublayer where HTR2A mRNA was consistently expressed at $140 \mathrm{~min}$ (arrow, Figures 8D-F), while they were coexpressed at $24 \mathrm{~min}$ (arrow, Figures 8A-C). Interestingly, $A R C$ mRNA expression was absent in this sublayer regardless of the time points (filled star, Figures $\mathbf{5 H}-\mathbf{J}$ ), while $c$-FOS mRNA was expressed uniformly over the entire layer IVC (i.e., layers IVC $\alpha$, IVC $\beta$, and this thin sublayer) (Figures $5 \mathbf{M}, \mathbf{N}$ ). These expression patterns clearly indicate that there are heterogeneity of the regulation of the activity-dependent gene 


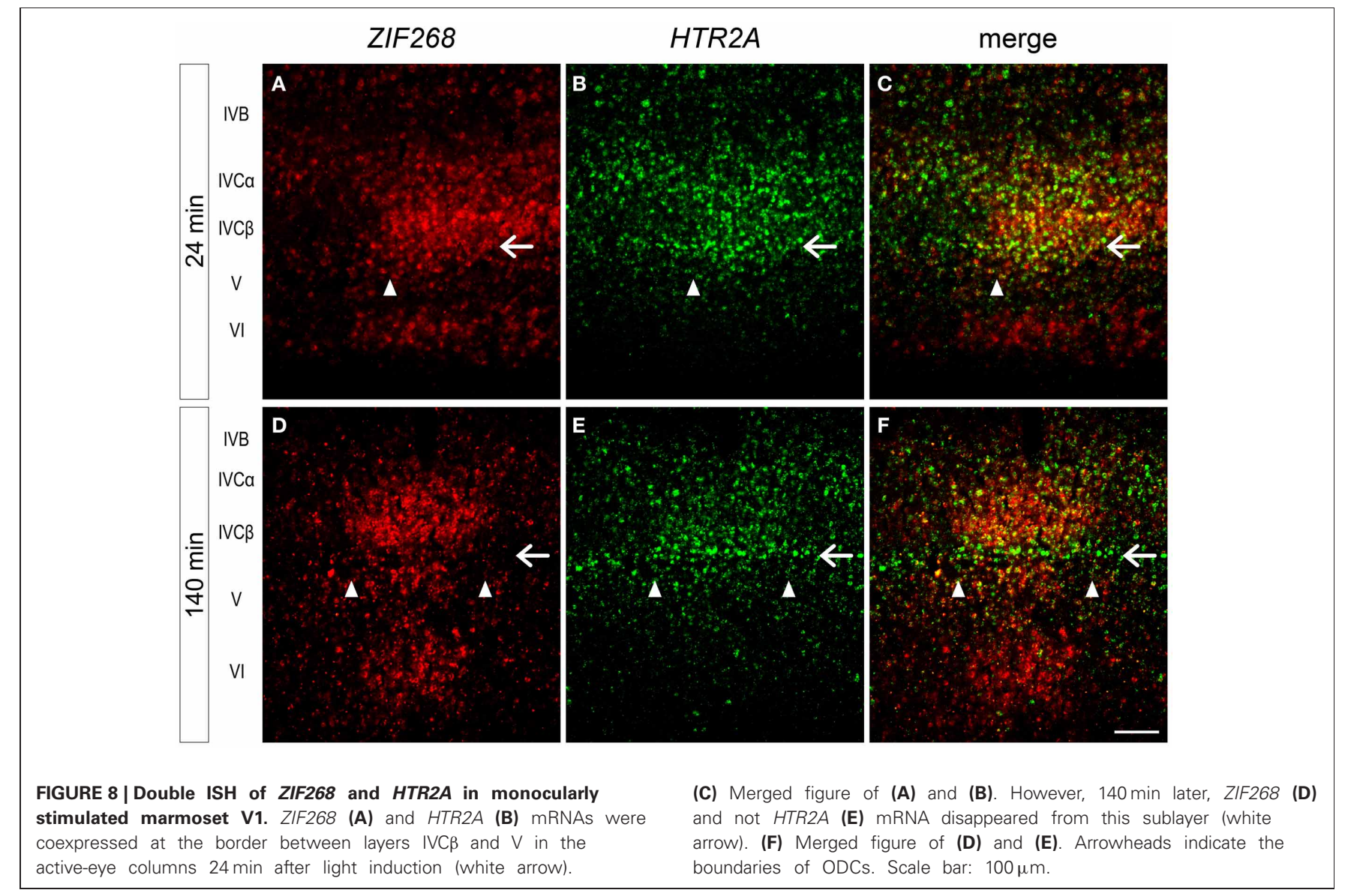

expression among the IEGs and the following gene expression in marmoset V1.

\section{DISCUSSION}

\section{SUMMARY OF THE RESULTS}

In this study, we carried out a series of monocular visual stimulation experiments using adult marmosets to investigate the time course of a group of activity-dependent genes in V1. The first conclusion from the series of experiments was that all activity-dependent genes clearly revealed the ocular dominance type of expression pattern in monocular stimulated marmoset V1. Second, the spontaneous retinal activity induced a certain level of HTR1B and HTR2A mRNA expressions without light stimulation. Third, we found that the expressions of the genes examined were regulated in layer- and sublayer-specific manner in the marmoset V1. Each IEG has unique time course of its expression in neurons of each layer in response to visual inputs and is coordinately but differently regulated in the same neuron. These findings illustrate the fine control mechanism of activitydependent gene regulation in marmoset V1. To the best of our knowledge, this is the first study to investigate a very rapid change of gene expression upon visual inputs in non-human primate V1.

\section{FUNCTIONAL OCULAR DOMINANCE COLUMNS IN ADULT MARMOSETS}

The existence of ODCs in adult marmosets has been controversial. It had been believed that marmosets have anatomical ODCs only transiently in their youth (Spatz, 1979, 1989). However, Sengpiel et al. (1996) suggested that ODCs could be observed in adulthood by monocular eyelid suture during development. Chappert-Piquemal et al. (2001) reported the anatomical ODCs in two out of four normal adult marmosets. As we mentioned in the Introduction, "Physiological ODCs" that are termed by these authors have been visualized with ZIF268 immunostaining (Markstahler et al., 1998). On the other hand, most cells in the marmoset V1 showed equal responsiveness through the two eyes by electrophysiological unit recording (Sengpiel et al., 1996). Optical imaging study also failed to detect reliable ODCs in adult marmosets (Roe et al., 2005; McLoughlin and Schiessl, 2006; Valverde Salzmann et al., 2012), despite that the existence of orientation columns (Roe et al., 2005; McLoughlin and Schiessl, 2006) and color domains (Valverde Salzmann et al., 2012) are demonstrated in adult marmoset by this method.

Although previous results suggest the existence of adult ODCs, the number of marmosets used to show ODCs are limited and ODCs are not always observed in adult marmosets as above described. In our study, all adult marmosets (11 in total) that received monocular TTX injection revealed clear ODCs by ISH for activity-dependent genes throughout layers II-VI (Figures 2, 5). We consider it important that the effect of TTX on mRNA expression of IEGs was not only restricted to layer IVC but also observed in all layers. This result suggests that most neurons 
in layers II-VI of marmoset V1 have ocular dominance along with columnar units as shown in other primates, and these ODCs were detectable by ISH of activity-dependent genes. Our finding is the first report showing structural segregation of the right and the left eye inputs outside layer IVC in marmoset V1, although previous reports using activity-dependent ZIF268 expression show ODCs in the capuchin monkey (Cebus) other than layer IVC (Silveira et al., 1996; Soares et al., 2005). The difference of IEG expression level between active- and inactive-eye columns outside layer IVC $\beta$, however, appeared to be less conspicuous than that of the Old World monkey (Chaudhuri and Cynader, 1993; Chaudhuri et al., 1995; Takahata et al., 2009). This indicates the lesser extent of left and right eye dominance in V1 of marmosets than that of Old World monkeys, which may be a reason why ODCs have not been detected consistently. We also consider that higher sensitivity of ISH method, as compared to ZIF268 immunostaining (Markstahler et al., 1998) may enable to detect ODCs outside layer IVC $\beta$ in all monocular deprived marmosets. In general, we could obtain better contrast of pictures by ISH than that by immunostaining (see Figure 5 and also Van der Gucht et al., 2007).

Since the discovery of V1 physiology including "ocular dominance" (Hubel and Wiesel, 1962), the functional ocular dominance is observed through mammals and the study has been targeted in the mouse as a model system to further dissecting the underlying molecular mechanisms (Hensch, 2005). However, no anatomical separation of the right and left LGN projection has been found in the mouse, rat or squirrel and partial separation into vertical cortical stripes in the cat. In primates, prosimian Galago and the representative Old World monkeys show clear anatomical ODCs (see the introductory summary by Spatz, 1979).

There has been controversy about ODCs of New World monkeys including marmosets, because most of them show little or weak anatomical separation of the projections from LGN (see Spatz, 1979; Livingstone, 1996). In spider monkeys (Ateles alter), however, Florence et al. (1986) demonstrated clear ODCs in layer IV, which casts an interesting question in regard to the phylogenic significance of ODCs in the New World monkey. Besides the marmoset (Callithrix), ODCs in adult animals were observed in the capuchin monkey (Cebus) (Silveira et al., 1996), the squirrel monkey (Saimiri) (Horton and Hocking, 1996), and the owl monkey (Aotus) (Rowe et al., 1978; Kaskan et al., 2007), whereas no ocular segregation was observed in the Saki monkey (Pitheeia) (Spatz, 1979; Florence et al., 1986; Livingstone, 1996). In addition our present study, we have recently reported ODCs in owl monkeys by monocular inactivation and gene expression study (Takahata et al., 2012). In this regard, the New World monkeys that have anatomical ocular separations (ODCs) in V1 may be indeed a major group. Although the rich and diverse environment where New World monkeys live have given rise to a quite variation of the visual systems, the ocular segregation in V1 may have evolved in the monkey visual system throughout the phylogeny of prosimians, New World monkeys, and Old World Monkeys. However, it remains for further future studies to test this notion including exceptional species.

\section{THE EXPRESSION PROPERTY OF HTR1B AND HTR2A GENES IN MARMOSETV1 SUGGESTS A CRITICAL ROLE OF SPONTANEOUS ACTIVITY}

We previously showed that HTR1B and HTR2A genes decreased their mRNA levels within $3 \mathrm{~h}$ of monocular inactivation by TTX in macaques (Watakabe et al., 2009). Our present data demonstrated the importance of spontaneous retinal activity over visual stimulation in the expression of these mRNAs in V1 (Figure 3). From this result, we suggest that the spontaneous retinal activitydependent regulation of HTR $1 B$ and HTR2A mRNAs may be a mechanism to ensure a certain level of their expressions in the thalamorecipient neurons in V1, regardless of visual stimulation. By in vivo electrophysiological experiments using specific agonist and antagonist for HTR1B and HTR2A receptor proteins, we previously reported that HTR1B and HTR2A exert modulatory effects in macaque $\mathrm{V} 1$, increase of $\mathrm{S} / \mathrm{N}$ ratio and gain control, respectively (Watakabe et al., 2009). Considering our present data, both receptors may always be present in V1 at a certain level, independent of the visual environment, to play these roles in macaque and marmoset V1. Xiang and Prince (2003) report the role of HTR3 receptors and HTR1A receptors of layer V pyramidal cells in rat visual cortex. The specific agonists for HTR3 and HTR1A cause opposite effects for spontaneous IPSC of pyramidal cells by controlling inward and outward currents of interneurons. Therefore, the combination of different subtypes of 5HT receptors may play similar roles in modulating the activity of excitatory neurons. However, it should be noted that HTR1B and HTR2A are expressed in excitatory neurons and their expressions are regulated in activity dependent manners (Watakabe et al., 2009), which features may have been added during the course of the evolution of the primate visual cortex.

We also note that the light-induced expression of HTR1B mRNA in V1 gradually increased upon light stimulation. This observation indicates that two different kinds of activities may control HTR1B mRNA. One is the spontaneous retinal activity and the other is the visual stimulation. Considering the rapid decreases upon TTX injection within $3 \mathrm{~h}$ (Watakabe et al., 2009), the offset of transcription for $H T R 1 B$ and $H T R 2 A$ is rapidly responded to a blocking spontaneous retinal activity. On the other hand, the slow induction of HTR1B mRNA by visual stimulation suggests that the response may be following to the expression of rapidly synthesized transcriptional factors including IEGs upon light induction. Therefore, our results strongly suggest that there are different transcriptional controls of $H T R 1 B$ and HTR2A from those of IEGs. However, what kinds of molecules are involved in the activity-dependent gene expression of $H T R 1 B$ and HTR2A remains to be revealed and we are currently studying for it.

\section{LAYER-SPECIFIC REGULATION OF ACTIVITY-DEPENDENT GENE EXPRESSION IN MARMOSET V1}

Our series of light induction experiments revealed a fine layerspecific regulation of each activity-dependent gene in marmoset V1 (Figures 4-8). Previous study suggests that Zif268 and JunD immunoreactivities exhibit different laminar patterns in the primate visual cortices under the normal reared condition (Okuno et al., 1997). Our results now revealed the evidence 
for multiple layer-specific regulation mechanisms in each gene evoked by the visual input in marmoset V1.

Several studies report the time course of IEG expression upon light exposure after dark-adaptation in V1. These studies, however, did not report differential time course for each layer. For example, investigation of c-Fos and Zif268 (mRNAs and immunostains) in rodents revealed rapid induction (within $30 \mathrm{~min}$ ) of IEGs upon light stimulation, consistent with our finding (Worley et al., 1991; Zangenehpour and Chaudhuri, 2002). Kaplan et al. (1996) reported that 1 or $4 \mathrm{~h}$ of light exposure induced both ZIF268 and c-FOS immunostaining in adult cat V1. However no layer difference was reported for either of these cases. In primates, 2 and $5 \mathrm{~h}$ light induction experiments have been performed for vervet monkeys (Chaudhuri and Cynader, 1993; Chaudhuri et al., 1995). The authors did not mention the changes of laminar distribution of ZIF268 immunoreactivity, it may be because the laminar expression pattern of ZIF268 changes little after $2 \mathrm{~h}$.

Two aspects of laminar differentiation should be considered to understand the activity-dependent profile in marmoset V1. First, there are highly layer-specific input-output pathways in primate V1. The inputs from parvo- and magnocellular layers of the LGN mainly enter layers IVC $\alpha$ and IVC $\beta$ of V1, as well as layers IVA, and VI (Nassi and Callaway, 2009). HTR1B was strongly expressed in layer IVC with a greater expression of IVC $\beta$ and subjected to spontaneous activity and light stimulation (Figure 3). This pattern of expression seems to well fit to the function of HTR1B receptors in the primary visual cortex in primates (Watakabe et al., 2009). In contrary, other activity-dependent genes ( $c$-FOS, ZIF268, ARC, and HTR2A) were expressed most of the layers, which suggests their multiple roles in marmoset V1. $\mathrm{V} 1$ also receives inputs from the pulvinar nucleus in layer I (Shipp, 2003; Callaway, 2004) or feedback projections from V2 in layer I (Rockland and Pandya, 1979). There is very little expression of all the activity-dependent genes examined in layer I. OCC1/FSTL1 which we first reported as the visual area-selective and activity dependent gene (Tochitani et al., 2001) is expressed at a significant level in the lower layer III in V2 that probably receives the pulvnar projection (Levitt et al., 1995). This difference of the expression within the pulvinar receiving neurons may be because thalamocortical fibers in layer I contact branches of the apical dendritic bouquets of deeper neurons

\section{REFERENCES}

Arckens, L., Van Der Gucht, E., Eysel, U. T., Orban, G. A., and Vandesande, F. (2000). Investigation of cortical reorganization in area 17 and nine extrastriate visual areas through the detection of changes in immediate early gene expression as induced by retinal lesions. J. Comp. Neurol. 425, 531-544.

Callaway, E. M. (2004). Feedforward, feedback and inhibitory connections in primate visual cortex. Neural. Netw. 17, 625-632.

Chappert-Piquemal, C., Fonta, C., Malecaze, F., and Imbert, M.
(2001). Ocular dominance columns in the adult New World Monkey Callithrix jacchus. Vis. Neurosci. 18, 407-412.

Chaudhuri, A., and Cynader, M. S. (1993). Activity-dependent expression of the transcription factor Zif268 reveals ocular dominance columns in monkey visual cortex. Brain Res. 605, 349-353.

Chaudhuri, A., Matsubara, J. A., and Cynader, M. S. (1995). Neuronal activity in primate visual cortex assessed by immunostaining for the transcription factor Zif268. Vis. Neurosci. 12, 35-50.

(Nieuwenhuys, 1994) and in layer I there may be no soma of the neurons that receive the thalamocortical fibers. Second, cell types that constitute each layer in primate $\mathrm{V} 1$ are heterogeneous (Thomson and Lamy, 2007). It is quite possible that the neurons in different layers possess different sets of regulatory factors for activity-dependent gene expression. For example, the lack of $A R C$ mRNA expression in layer IVC but not in other layers for the initial 24 min suggests that different signaling cascades and transcriptional factors are involved in these neurons. Since different types of neurons coexist in each layer (Thomson and Lamy, 2007). There might be some neural mechanisms to orchestrate activity-dependent transcription among different subtypes of neurons.

In this regard, the sublayer of very bottom part of layer IVC was intriguing, in that ZIF268, HTR2A, and ARC mRNAs exhibited differential responses to visual stimulation (Figures 4, 5, 8). Presence of thin sublayer of Zif268 mRNA and protein at the same sublamina position has also been observed in vervet monkeys (Chaudhuri and Cynader, 1993; Chaudhuri et al., 1995), and in macaque monkeys (Takahata et al., 2008, 2009). These studies raise the possibility that gene-specific and layer-specific responses to visual stimulation may be conserved among certain primates.

Finally, our results that showed the different temporal and spatial regulation of IEGs, HTR1B, and HTR2A in marmoset V1 upon the change of retinal inputs suggest that precise cell- and layer-specific transcriptional control of activity-dependent genes is likely to contribute to differential roles of neurons of each layer in visual processing, which should play roles in the formation and maintenance of the highly stratified visual cortex of primates, and thereby to their visual functions.

\section{ACKNOWLEDGMENTS}

We thank Drs. Yusuke Komatsu and Masafumi Takaji in our laboratory for help with marmoset handling and operation. This work was supported by Scientific Research on Innovative Areas "Neural Diversity and Neocortical Organization" from the Ministry of Education, Culture, Sports, Science (to Tetsuo Yamamori) and "Strategic Research Program for Brain Sciences (Highly Creative Animal Model Development for Brain Science)" from the Ministry of Education, Culture, Sports, Science, and Technology of Japan.

Collins, C. E., Leitch, D. B., Wong, P., Kaas, J. H., and HerculanoHouzel, S. (2012). Faster scaling of visual neurons in cortical areas relative to subcortical structures in non-human primate brains. Brain Struct. Funct. doi: 10.1007/s00429012-0430-5. [Epub ahead of print].

Flavell, S. W., and Greenberg, M. E. (2008). Signaling mechanisms linking neuronal activity to gene expression and plasticity of the nervous system. Annu. Rev. Neurosci. 31, 563-590.

Flicek, P., Amode, M. R., Barrell, D., Beal, K., Brent, S., Carvalho-Silva,
D., et al. (2012). Ensembl 2012. Nucleic. Acids. Res. 40, D84-D90.

Florence, S. L., Conley, M., and Casagrande, V. A. (1986). Ocular dominance columns and retinal projections in New World spider monkeys (Ateles ater). J. Comp. Neurol. 243, 234-248.

Fowler, T., Sen, R., and Roy, A. L. (2011). Regulation of primary response genes. Mol. Cell 44, 348-360.

Hirokawa, J., Bosch, M., Sakata, S., Sakurai, Y., and Yamamori, T. (2008). Functional role of the secondary visual cortex in 
multisensory facilitation in rats. Neuroscience 153, 1402-1417.

Hensch, T. K. (2005). Critical period plasticity in local cortical circuits. Nat. Rev. Neurosci. 6, 877-888.

Horton, J. C., and Hocking, D. R. (1996). Anatomical demonstration of ocular dominance columns in striate cortex of the squirrel monkey. J. Neurosci. 16, 5510-5522.

Hubel, D. H., and Wiesel, T. N. (1962). Receptive fields, binocular interaction and functional architecture in the cat's visual cortex. J. Physiol. 160, 106-154.

Hubel, D. H., and Wiesel, T. N. (1977). Ferrier lecture. Functional architecture of macaque monkey visual cortex. Proc. R. Soc. Lond. B Biol. Sci. 198, 1-59.

Joels, M., and de Kloet, E. R. (1992). Control of neuronal excitability by corticosteroid hormones. Trends. Neurosci. 15, 25-30.

Kaplan, I. V., Guo, Y., and Mower, G. D. (1996). Immediate early gene expression in cat visual cortex during and after the critical period: differences between EGR-1 and Fos proteins. Brain Res. Mol. Brain Res. $36,12-22$.

Kaskan, P. M., Lu, H. D., Dillenburger, B. C., Roe, A. W., and Kaas, J. H. (2007). Intrinsic-signal optical imaging reveals cryptic ocular dominance columns in primary visual cortex of New World owl monkeys. Front. Neurosci. 1, 67-75. doi: 10.3389/neuro.01/1.1.005.2007

Kent, W. J. (2002). BLAT-the BLASTlike alignment tool. Genome Res. 12, 656-664.

Kent, W. J., Sugnet, C. W., Furey, T. S., Roskin, K. M., Pringle, T. H., Zahler, A. M., et al. (2002). The human genome browser at UCSC. Genome. Res. 12, 996-1006.

Komatsu, Y., Watakabe, A., Hashikawa, T., Tochitani, S., and Yamamori, T. (2005). Retinol-binding protein gene is highly expressed in higherorder association areas of the primate neocortex. Cereb. Cortex 15, 96-108.

Kovacs, K. J. (2008). Measurement of immediate-early gene activation- cfos and beyond. J. Neuroendocrinol. 20, 665-672.

Levitt, J. B., Yoshioka, T., and Lund, J. S. (1995). Connections between the pulvinar complex and cytochrome oxidase-defined compartments in visual area V2 of macaque monkey. Exp. Brain Res. 104, 419-430.

Liang, F., Hatanaka, Y., Saito, H., Yamamori, T., and Hashikawa, T. (2000). Differential expression of gamma-aminobutyric acid type $\mathrm{B}$ receptor-1a and - $1 \mathrm{~b}$ mRNA variants in GABA and non-GABAergic neurons of the rat brain. J. Comp. Neurol. 416, 475-495.

Livingstone, M. S. (1996). Ocular dominance columns in New World monkeys. J. Neurosci. 16, 2086-2096.

Livingstone, M. S., and Hubel, D. H. (1984). Anatomy and physiology of a color system in the primate visual cortex. J. Neurosci. 4, 309-356.

Markstahler, U., Bach, M., and Spatz, W. B. (1998). Transient molecular visualization of ocular dominance columns (ODCs) in normal adult marmosets despite the desegregated termination of the retino-geniculocortical pathways. J. Comp. Neurol. 393, 118-134.

McLoughlin, N., and Schiessl, I. (2006). Orientation selectivity in the common marmoset (Callithrix jacchus): the periodicity of orientation columns in V1 and V2. Neuroimage 31, 76-85.

Montero, V. M., and Jian, S. (1995). Induction of $\mathrm{c}$-fos protein by patterned visual stimulation in central visual pathways of the rat. Brain Res. 690, 189-199.

Morgan, J. I., Cohen, D. R., Hempstead, J. L., and Curran, T. (1987). Mapping patterns of $\mathrm{c}$-fos expression in the central nervous system after seizure. Science 237, 192-197.

Nassi, J. J., and Callaway, E. M. (2009). Parallel processing strategies of the primate visual system. Nat. Rev Neurosci. 10, 360-372.

Nieuwenhuys, R. (1994). The neocortex. An overview of its evolutionary development, structural organization and synaptology. Anat. Embryol. (Berl.) 190, 307-337.

Okuno, H., Kanou, S., Tokuyama, W., Li, Y. X., and Miyashita, Y. (1997). Layer-specific differential regulation of transcription factors Zif268 and Jun-D in visual cortex V1 and V2 of macaque monkeys. Neuroscience 81 , 653-666.

Rockland, K. S., and Pandya, D. N. (1979). Laminar origins and terminations of cortical connections of the occipital lobe in the rhesus monkey. Brain Res. 179, 3-20.

Roe, A. W., Fritsches, K., and Pettigrew, J. D. (2005). Optical imaging of functional organization of $\mathrm{V} 1$ and $\mathrm{V} 2$ in marmoset visual cortex. Anat. Rec. A. Discov. Mol. Cell. Evol. Biol. 287, 1213-1225.

Rosen, K. M., McCormack, M. A., Villa-Komaroff, L., and Mower, G. D. (1992). Brief visual experience induces immediate early gene expression in the cat visual cortex.
Proc. Natl. Acad. Sci. U.S.A. 89, 5437-5441.

Rowe, M. H., Benevento, L. A., and Rezak, M. (1978). Some observations on the patterns of segregated geniculate inputs to the visual cortex in New World primates: an autoradiographic study. Brain Res. 159, 371-378.

Sakata, S., Kitsukawa, T., Kaneko, T., Yamamori, T., and Sakurai, Y. (2002). Task-dependent and cell-type-specific Fos enhancement in rat sensory cortices during audio-visual discrimination. Eur. J. Neurosci. 15, 735-743.

Sasaki, E., Suemizu, H., Shimada, A., Hanazawa, K., Oiwa, R., Kamioka, M., et al. (2009). Generation of transgenic non-human primates with germline transmission. Nature 459, 523-527.

Sengpiel, F., Troilo, D., Kind, P. C. Graham, B., and Blakemore, C. (1996). Functional architecture of area 17 in normal and monocularly deprived marmosets (Callithrix jacchus). Vis. Neurosci. 13, 145-160.

Sheng, M., and Greenberg, M. E. (1990). The regulation and function of c-fos and other immediate early genes in the nervous system. Neuron 4, 477-485.

Shipp, S. (2003). The functional logic of cortico-pulvinar connections. Philos. Trans. R. Soc. Lond. B Biol. Sci. 358, 1605-1624.

Silveira, L. C., de Matos, F. M., PontesArruda, A., Picanco-Diniz, C. W. and Muniz, J. A. (1996). Late development of Zif268 ocular dominance columns in primary visual cortex of primates. Brain Res. 732 , 237-241.

Soares, J. G., Pereira, A. C., Botelho, E. P., Pereira, S. S., Fiorani, M. and Gattass, R. (2005). Differential expression of Zif268 and c-Fos in the primary visual cortex and lateral geniculate nucleus of normal Cebus monkeys and after monocular lesions. J. Comp. Neurol. 482, 166-175.

Spatz, W. B. (1979). The retinogeniculo-cortical pathway in Callithrix. II. The geniculo-cortical projection. Exp. Brain. Res. 36, 401-410.

Spatz, W. B. (1989). Loss of ocular dominance columns with maturity in the monkey, Callithrix jacchus Brain. Res. 488, 376-380.

Takahata, T., Hashikawa, T., Higo, N., Tochitani, S., and Yamamori, T. (2008). Difference in sensory dependence of occl/Follistatinrelated protein expression between macaques and mice. J. Chem. Neuroanat. 35, 146-157.
Takahata, T., Komatsu, Y., Watakabe, A., Hashikawa, T., Tochitani, S., and Yamamori, T. (2009). Differential expression patterns of occl-related genes in adult monkey visual cortex. Cereb. Cortex 19, 1937-1951.

Takahata, T., Higo, N., Kaas, J. H., and Yamamori, T. (2009). Expression of immediate-early genes reveals functional compartments within ocular dominance columns after brief monocular inactivation. Proc. Natl. Acad. Sci. U.S.A. 106, 12151-12155.

Takahata, T., Shukla, R., Yamamori, T., and Kaas, J. H. (2012). Differential expression patterns of striate cortex-enriched genes among old world, new world, and prosimian primates. Cereb. Cortex 22, 2313-2321.

Thomson, A. M., and Lamy, C. (2007). Functional maps of neocortical local circuitry. Front. Neurosci. 1, 19-42. doi: 10.3389.neuro.01/1.1.002.2007

Tochitani, S., Liang, F., Watakabe, A., Hashikawa, T., and Yamamori, T. (2001). The occl gene is preferentially expressed in the primary visual cortex in an activity-dependent manner: a pattern of gene expression related to the cytoarchitectonic area in adult macaque neocortex. Eur. J. Neurosci. 13, 297-307.

Valverde Salzmann, M. F., Bartels, A., Logothetis, N. K., and Schuz, A. (2012). Color blobs in cortical areas $\mathrm{V} 1$ and $\mathrm{V} 2$ of the new world monkey Callithrix jacchus, revealed by non-differential optical imaging. J. Neurosci. 32, 7881-7894.

Van der Gucht, E., Hof, P. R., Van Brussel, L., Burnat, K., and Arckens, L. (2007). Neurofilament protein and neuronal activity markers define regional architectonic parcellation in the mouse visual cortex. Cereb. Cortex 17, 2805-2819.

Warner, C. E., Kwan, W. C., and Bourne, J. A. (2012). The early maturation of visual cortical area MT is dependent on input from the retinorecipient medial portion of the inferior pulvinar. J. Neurosci. 32, 17073-17085

Watakabe, A., Ichinohe, N., Ohsawa, S., Hashikawa, T., Komatsu, Y., Rockland, K. S., et al. (2007). Comparative analysis of layerspecific genes in Mammalian neocortex. Cereb. Cortex 17, 1918-1933.

Watakabe, A., Komatsu, Y., Sadakane, O., Shimegi, S., Takahata, T., Higo, N., et al. (2009). Enriched expression of serotonin $1 \mathrm{~B}$ and $2 \mathrm{~A}$ receptor genes in macaque visual cortex 
and their bidirectional modulatory effects on neuronal responses. Cereb. Cortex 19, 1915-1928.

Watakabe, A., Komatsu, Y., Ohsawa, S., and Yamamori, T. (2010). Fluorescent in situ hybridization technique for cell type identification and characterization in the central nervous system. Methods 52, 367-374.

Watakabe, A., Kato, S., Kobayashi, K., Takaji, M., Nakagami, Y., Sadakane, O., et al. (2012). Visualization of cortical projection neurons with retrograde TET-Off lentiviral Vectorvector. PLOS ONE 7:e46157. doi: 10.1371/journal.pone.0046157
Worley, P. F., Christy, B. A., Nakabeppu, Y., Bhat, R. V., Cole, A. J., and Baraban, J. M. (1991). Constitutive expression of zif268 in neocortex is regulated by synaptic activity. Proc. Natl. Acad. Sci. U.S.A. 88, 5106-5110.

Xiang, Z., and Prince, D. A. (2003). Heterogeneous actions of serotonin on interneurons in rat visual cortex. J. Neurophysiol. 89, 1278-1287.

Yamamori, T. (2011). Selective gene expression in regions of primate neocortex: implications for cortical specialization. Prog. Neurobiol. 94, 201-222.
Zangenehpour, S., and Chaudhuri, A. (2002). Differential induction and decay curves of c-fos and zif268 revealed through dual activity maps. Brain. Res. Mol. Brain. Res. 109, 221-225.

Conflict of Interest Statement: The authors declare that the research was conducted in the absence of any commercial or financial relationships that could be construed as a potential conflict of interest.

Received: 03 December 2012; accepted: 03 March 2013; published online: 09 April 2013.
Citation: Nakagami Y, Watakabe A and Yamamori $T$ (2013) Monocular inhibition reveals temporal and spatial changes in gene expression in the primary visual cortex of marmoset. Front. Neural Circuits 7:43. doi: 10.3389/fncir. 2013.00043

Copyright (C) 2013 Nakagami, Watakabe and Yamamori. This is an open-access article distributed under the terms of the Creative Commons Attribution License, which permits use, distribution and reproduction in other forums, provided the original authors and source are credited and subject to any copyright notices concerning any third-party graphics etc. 